\title{
Human-induced pluripotent stem cell-derived cardiomyocytes, 3D cardiac structures, and heart-on-a-chip as tools for drug research
}

\author{
Kalina Andrysiak ${ }^{1}$ • Jacek Stępniewski ${ }^{1}$ • Józef Dulak ${ }^{1}$ (D \\ Received: 9 December 2020 /Revised: 1 February 2021 / Accepted: 3 February 2021 /Published online: 24 February 2021 \\ (C) The Author(s) 2021
}

\begin{abstract}
Development of new drugs is of high interest for the field of cardiac and cardiovascular diseases, which are a dominant cause of death worldwide. Before being allowed to be used and distributed, every new potentially therapeutic compound must be strictly validated during preclinical and clinical trials. The preclinical studies usually involve the in vitro and in vivo evaluation. Due to the increasing reporting of discrepancy in drug effects in animal and humans and the requirement to reduce the number of animals used in research, improvement of in vitro models based on human cells is indispensable. Primary cardiac cells are difficult to access and maintain in cell culture for extensive experiments; therefore, the human-induced pluripotent stem cell-derived cardiomyocytes (hiPSC-CMs) became an excellent alternative. This technology enables a production of high number of patient- and disease-specific cardiomyocytes and other cardiac cell types for a large-scale research. The drug effects can be extensively evaluated in the context of electrophysiological responses with a use of well-established tools, such as multielectrode array (MEA), patch clamp, or calcium ion oscillation measurements. Cardiotoxicity, which is a common reason for withdrawing drugs from marketing or rejection at final stages of clinical trials, can be easily verified with a use of hiPSC-CM model providing a prediction of human-specific responses and higher safety of clinical trials involving patient cohort. Abovementioned studies can be performed using two-dimensional cell culture providing a high-throughput and relatively lower costs. On the other hand, more complex structures, such as engineered heart tissue, organoids, or spheroids, frequently applied as co-culture systems, represent more physiological conditions and higher maturation rate of hiPSC-derived cells. Furthermore, heart-on-a-chip technology has recently become an increasingly popular tool, as it implements controllable culture conditions, application of various stimulations and continuous parameters read-out. This paper is an overview of possible use of cardiomyocytes and other cardiac cell types derived from hiPSC as in vitro models of heart in drug research area prepared on the basis of latest scientific reports and providing thorough discussion regarding their advantages and limitations.
\end{abstract}

Keywords Cardiomyocytes · hiPSC-CMs · Organoids · Heart-on-a-chip · Drug research · Cardiotoxicity · Spheroids · Engineered heart tissue $\cdot$ EHT $\cdot$ 3D structures $\cdot$ Stem cells $\cdot$ hiPSC $\cdot$ Body-on-a-chip

\section{Introduction}

Drug approval is always preceded by preclinical in vitro and in vivo research followed by human clinical testing aiming to confirm effectiveness and safety of the drug. This is a multistage process, as it requires evaluation of multiple parameters, including effective dosage regimens, bioavailability, food-

Józef Dulak

jozef.dulak@uj.edu.pl

1 Department of Medical Biotechnology, Faculty of Biochemistry, Biophysics and Biotechnology, Jagiellonian University, Kraków, Poland and other drugs interactions and side effects assessment, known as pharmacokinetics/pharmacodynamics modeling. First preclinical testing is performed in vitro on cell line models and in vivo on animal models and both these experimental models have their advantages and limitations. So far, a large number of drug responses are studied in animals, predominantly mice and rats, as it enables comprehensive exploration of its effects on multiple metabolic processes occurring in many organs with particular emphasis on hepatotoxicity and crossing the blood-brain barrier. Moreover, genetically engineered animals are commonly available; therefore, therapeutic agents considered as a potential treatment for a specific genetic disorder can be evaluated on the animal model of this particular disease. On the other hand, in case of some disease 
entities, such models are not available or they do not accurately reflect the mechanisms or disease severity (reviewed by Van der Worp et al. [190] and Houser et al. [74], discussed in more details, on the basis of studies using animal models of stroke by Gladstone et al. [58]). Furthermore, straindependent effects observed in experimental animals $[12,17$, $27,102]$ may lead to incorrect conclusions. Some medicines directly applied to people may exert opposed or unintended upshots resulting from biochemical and metabolic differences between animals and humans.

The main advantage of cellular models is that they facilitate high-throughput screening of chemical compounds libraries or their various combinations with relatively lower costs and limited number of animals used for experiments. Notwithstanding, such models should be continuously improved and adapted to support high sensitivity and credibility of observed outcomes with special emphasis on foundational assumptions of personalized medicine. Investigations of organ-specific responses are routinely performed on immortalized cell lines, as their in vitro culture is relatively simple due to fast cell divisions and not very high nutritional requirements; however, frequent differences in either observed drug effectiveness or sensitivity of cells to a given compound do not allow for translation of identified outcomes to healthy cells. Another common cell source, primary cell lines, which are obtained directly from human tissues, are often troublesome in accession (due to the need for internal organ biopsy) and in vitro culture (due to the frequently occurring change of phenotype caused by cell differentiation, entering into senescence or overgrowth of non-target cells present as contaminants, e.g., fibroblasts).

Since not all tissue types are easily available for studies, human-induced pluripotent stem cells (hiPSCs) established in 2007 by the research team of Shinya Yamanaka [177] have become a good alternative for studies of patient- or diseasespecific cells. They can be differentiated into many cell types, including cardiomyocytes, hepatocytes, and distinct neuron cell types with relatively high efficiency, providing extensive material for studies. This approach is particularly valuable for the research on heart diseases, as the heart biopsies are almost inaccessible, while the available tissue samples obtained from heart transplantation have frequently some additional abnormalities, as they come from failing hearts. Moreover, cardiomyocytes are non-dividing cells; therefore, it is impossible to multiply them during in vitro culture and their resource is very limited. hiPSC-derived cardiomyocytes (hiPSC-CMs) also show restricted proliferation capacity, however, as hiPSCs divide easily, efficient differentiation of large numbers of hiPSCs and additional steps of hiPSC-CMs purification accordingly to well-established protocols ([66, 182], reviewed by Ban et al. [10]) can solve this problem.

Cardiac and cardiovascular diseases are the main cause of death worldwide; therefore, searching of new molecular targets and development of novel, more specific and efficient drugs is a priority. Additionally, it was shown that plenty of already marketed medicaments (with the particular emphasis on chemotherapeutic agents) may show adverse cardiovascular effects, leading to cardiac arrhythmias and heart failure. With this in mind, newly discovered drugs should be validated on a regular basis in the context of cardiotoxicity criteria.

This paper aims to review the currently available models (Fig. 1) used for in vitro drug research in the context of cardiovascular drug development.

\section{Methods and tools for studies of drug response in hiPSC-derived cardiomyocytes}

Since the cardiomyocytes are electrically active cells and many abnormalities in their proper functioning results from impaired electrophysiological activity, most experimental setups are based on determination of electrophysiological properties of those cells. Wide range of available tools (Fig. 2) enables comprehensive analyses of multiple parameters, continuously recorded in response to pharmacological stimulation.

Multi-electrode arrays (sometimes also referred to as micro-electrode arrays) (MEAs) are among the most widely used devices in this field. They consist of tens or even thousands of electrodes located in close proximity on a relatively small area, depending on the design, as they are available in the form of individual wells or multi-well plates. Cardiomyocytes are seeded directly onto a platform with electrodes and measurements are performed after the time required for cells adaptation and formation of syncytium. The system is designed in order to record the basal spontaneous activity of the cells through detection of changes in extracellular field potential and is fully integrated with a software for data analysis. Obtained measurements allow assessment of the electrophysiological functions of the cells in several parameters, such as beating rate, depolarization, repolarization, and presence of arrhythmic events. Specifically, MEA generates field potential waveforms (resembling clinical electrocardiography), quantitatively presented as QT interval (QT) and field potential duration (FPD). Their thorough analysis allows determining whether a given drug blocks or activates one of the ion channels involved in the action potential generation. For instance, it was reported that some drugs, such as antipsychotic medicaments or tricyclic antidepressants, can induce QT prolongation and hence increase a risk of proarrhythmic Torsade de Pointes (TdP) occurrence, leading to life-threatening cardiac arrest (reviewed by Sicouri and Antzelevitch [170]). On the molecular level, it is usually implicated with human hERG (human ether-à-go-go related gene) potassium channel blockade, although there are also other mechanisms entailing such effects, as in some classes of arrhythmic agents, it is induced through activation or inhibition of calcium, sodium, or other potassium channels $([38,79,81,119,120,137])$ 
Fig. 1 Main advantages and limitations of available cellular models based on cardiomyocytes and other cell types present in heart for the use in cardiotoxicity studies and new drug development

In vitro models based on cardiac cell types differentiated from human induced pluripotent stem cells (hiPSC) for drug research

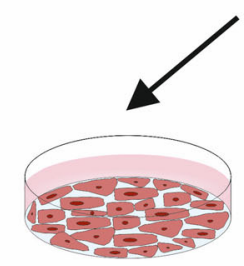

2D cell culture

high throughput,

$\checkmark$ methodologically undemanding, does not require additional skills,

$X$ far from physiological conditions,

$X$ Immature phenotype of hiPSC-derived cells,

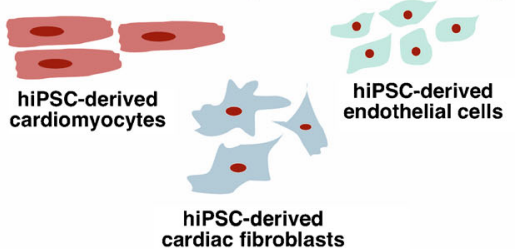

cardiac fibroblasts

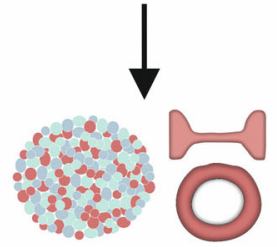

3D cell culture (spheroids/engineered heart tissue)

resembles physiological conditions,

$\checkmark$ provides more mature phenotype of hiPSCderived cells,

$X$ hypoxic conditions present in the inner part of structure, $X$ impeded imaging of cells located inside,

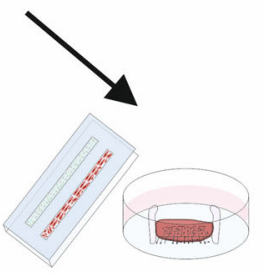

Heart-on-a-chip technology

built-in read-outs enabling continuous data collection, possible application of mechanical and electrical stimulation, possible cell interaction studies with physical separation of different cell types,

$X$ air bubbles often appearing in channels,
An alternative solution for in vitro electrophysiological measurements, though slightly more complicated, is patchclamp technology. This method differs from the previous one in that the action potential signals are measured from single cells and a very thin glass micropipette is used for this. To perform the analyses, the micropipette tip is set in a very tight contact with the cell membrane, leaving no space in between. Hence, all the ions pass the ion channels and a resulting current is recorded by an electrode placed in the micropipette, indicating the opening, closing, or inactivation of the channels [204]. Besides, additional modifications of the setups are possible - the whole patch clamp, inside-out and outside-out recording, and two measurement modes voltage clamp and current clamp [204], enabling the comprehensive evaluation of functioning of distinct ion channels in response to drug stimulation and understanding of underlying mechanisms in more details. Given that the quantitative data are based on generated action potential (AP) shapes, they are commonly described as action potential duration (APD), AP peak, AP amplitude, action potential at $20,50 \%$ or $90 \%$ repolarization (abbreviated as APD20, ADP50 and APD90, respectively), maximal diastolic potential (MDP), beat rate and current-voltage (I-V) characteristic curve. It was reported that action potential duration corresponds with field potential duration registered by MEA [65]. Prolonged APD, related to QT prolongation, equivalently induces the arrhythmic events, and the APD20/50/90 duration ratio allows to identify the prolonged phase. For instance, the early after depolarizations (EADs) observed in phase 2 and 3 of the action potential are implicated by exaggerated opening of calcium and sodium channels and contribute to increased risk of ventricular tachycardia (see [9] for a review). Nevertheless, the main limitation of this method is its low throughput due to the need for individual cell measurement.

Calcium imaging is another widely applied method on account of the fact that it enables an evaluation of changes in intracellular calcium ions concentrations, underlying a process of excitation-contraction coupling (ECC) and cardiac contractions. Abnormalities in calcium dynamics trigger myocardial dysfunction and heart failure. Mutations in cardiac ryanodine 
Fig. 2 The most common tools for evaluation of drug effects in hiPSC-CM-based in vitro models

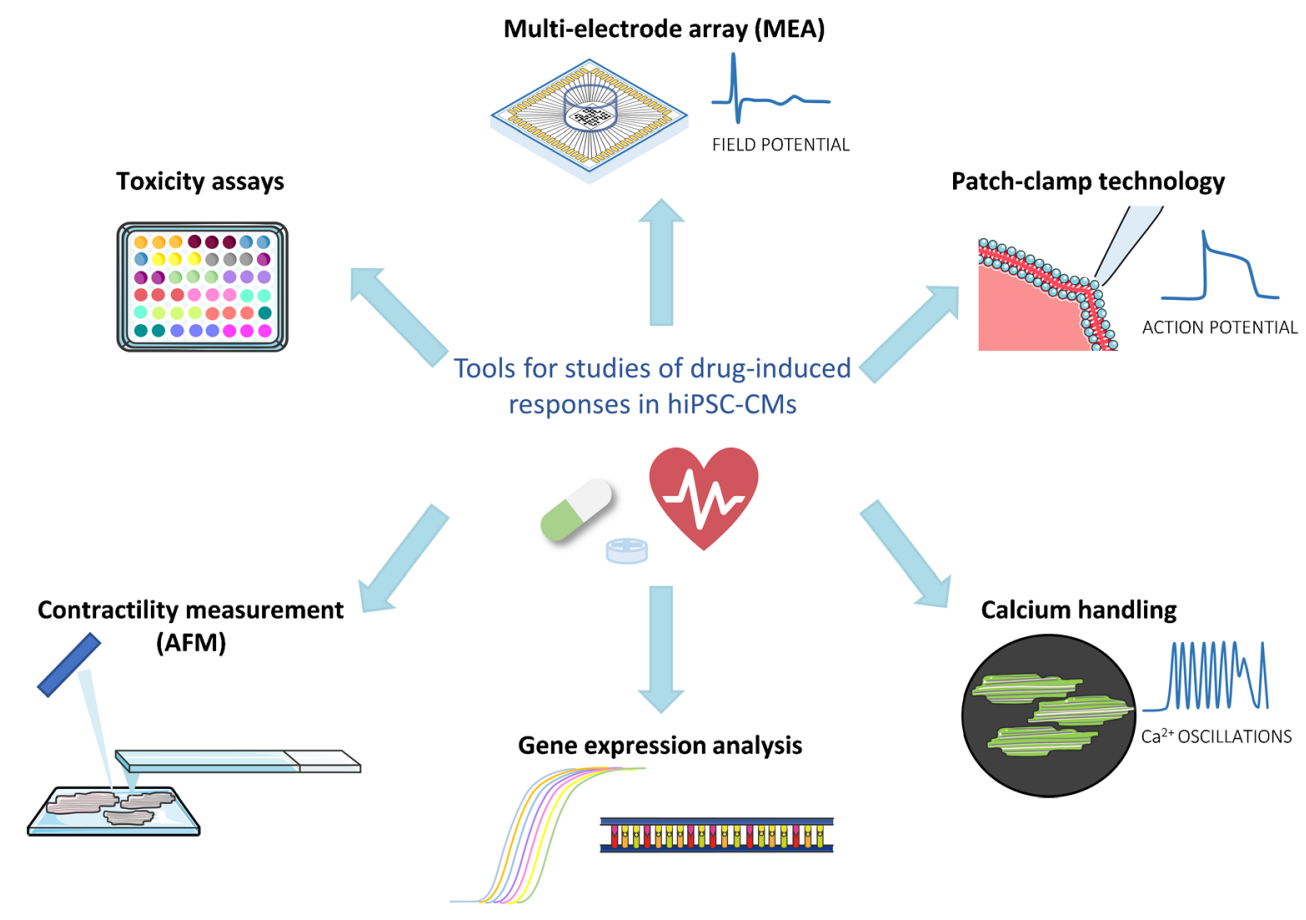

receptor (RyR2), a crucial channel releasing calcium from the sarcoplasmic reticulum (SR) to the cytoplasm and thus involved in ECC, for instance, result in catcholaminergic polymorphic ventricular tachycardia (CPVT). It is an inherited arrhythmogenic condition with high risk of sudden cardiac death for which application of patient-specific hiPSC-CMs provided reliable model of unstable SR calcium storage [47, $75,172]$. In vitro, calcium oscillations in cells are measured by the use of calcium flux indicators, such as Fluo-4, Fura-2, or Rhod-3, which are the most commonly used dyes. When bound to calcium, they emit fluorescence, the intensity of which corresponds to the $\mathrm{Ca}^{2+}$ concentration. As in previous methods, dedicated for these measurements software allows to monitor differences in generated waveforms according to parameters such as calcium transient duration and amplitude, calcium transient duration at $90 \%$ of decay after the peak amplitude (CTD90), beat rate or presence of arrhythmic events [91]. Furthermore, the waveforms represent some characteristics, such as EADs, beating arrest or fibrillation incidences (reviewed by Kistamás et al. [87]).

The contractile properties of hiPSC-cardiomyocytes can be measured with a use of atomic force microscopy (AFM), providing a comprehensive quantitative data. It was shown that it can be applied both for the studies of disease-specific hiPSCcardiomyocytes and for drug research enabling the assessment of mechanobiological properties of cells after various stimulations $[4,109,140]$. Other popular methods involve magnetic or fluorescent beads [152, 195], polyacrylamide gels [152], or muscular thin films $[6,61]$. Rodriguez et al. and Beussman et al. proposed a micropost array-based platform for multidirectional force measurement of the single cardiomyocytes, which are seeded onto a range of elastic micropost tips detecting the contractile forces of the cell $[16,155]$. In order to measure the contractile properties of $3 \mathrm{D}$ engineered tissues they can be assembled into a silicon rubbers and their deflections are quantified [50].

The abovementioned method adopting fluorescent dyes can be employed as a substitute approach for action potential measurements. Electrically active cells, such as cardiomyocytes, can be stained with potentiometric, voltage-sensitive dyes, for instance FluoVolt, di-4-ANEPPS or ANNINE-6plus, which visualize changes in membrane potential, providing a highthroughput optical recording-based measurements ([73], reviewed by Herron et al. [69]). Using fluorescent dyes of different absorption and emission spectra it is possible to simultaneously measure the action potential parameters together with others, such as abovementioned calcium handling or contraction force. Such optical-based measurements can be also performed without additional manipulation or treatment (staining) of cells. Computational resources enable analysis of contraction phenotype on a basis of processed microscope recordings through the motion tracking. hiPSC-CMs beating characteristic can be also evaluated with a use of the force transducers and automated xCELLigence $\AA$ RTCA Cardio platform based on impedance monitoring. Taken together, cardiac optical recording-based analyses provide quick and easy system for drug effect evaluation. Van Meer et al. highlights, though, the importance of simultaneous analysis of such data together with other parameters measurements (typically by designing a suitable algorithm) [121]. Besides, this type of imaging may seem difficult to adapt to $3 \mathrm{D}$ cultures due to the limited imaging capabilities. This issue can be comparatively solved by use of confocal microscopy; 
however, there are some alternative solutions available. Daily et al. [41] established an optimized protocol of 3D CMs cultures preparation, cell loading protocol and measurement registration by a plate reader, facilitating precise action potential detection. Nitsch et al., in turn, proposed an optical video-based measurements of contraction properties of 3D structures [132].

Due to the fact that all drug development laboratories use analogous methods, tools and parameters, validated data quantification systems, and consistent criteria for the assessment of drug-induced effects are necessary. Thereby, novel scoring systems and software tools are developed $[70,91,161]$ on the basis of most commonly used electrophysiological function parameters. To illustrate, Kopljar et al. proposed a system that converts parameters obtained from calcium handling analysis to assess the risk of unintended reactions such as drug-induced arrhythmias and on this basis classifies compounds as possessing no, low, high or very high hazard score prediction [91]. Despite the use of various measurement techniques, calculations and presentation of results can be standardized thanks to ready-made, validated softwares based on accurately developed algorithms. Hence, MUSCLEMOTION software was established to provide a tool for automated quantitative analysis of cell contractions [161]. SarcTrack software, in turn, facilitates the analysis of fluorescently stained hiPSC-CMs sarcomere contractions and relaxation characteristics [181].

Besides the electrophysiological analysis, determination of gene expression level is a remarkable alternative for further evidence of the drug effect. This is particularly important for the drugs that affect the interaction of individual ion channels or receptors. Additionally, wide range of methods used for gene expression analysis allow to identify an altered expression of individual channel subunit or receptor and hence to recognize a new molecular target for the treatment of a particular disease.

Cardiac toxicity induced as a side effect of pharmaceutical agents can be evaluated with a use of above systems through observation of cardiac contractility abnormalities, i.e., suppression of contractions, increased beating rate or arrhythmia induction. Moreover, it can be manifested by high level of cell death, which can be calculated with a use of conventional cell viability and cytotoxicity assays.

Summarizing, the abovementioned methods enable the assessment of baseline abnormalities occurring in a given disease entity, which allows designing new treatment strategies. In addition, the high throughput of the presented methods allows testing of existing drug libraries in appropriate models to examine multidimensional effects.

\section{hiPSC-derived cardiomyocytes application for drug research}

There is a considerable amount of literature on use of hiPSCderived cardiomyocytes in disease modelling and regenerative medicine. Various approaches of cardiac differentiation have been proposed both in monolayer system [24, 105] and through the embryoid bodies [22, 25], and they are predominantly based on WNT signaling pathway inhibition. High differentiation efficiency (up to 90\%) allows obtaining a great number of cardiomyocytes for large-scale testing. Analyses aimed at developing new drugs for the treatment of defined genetic disease can be performed with a use of patient-specific iPSC-derived cardiomyocytes carrying the mutation-of-interest. This approach is relatively easy to implement, as only a few milliliters of peripheral blood is needed to generate hiPSCs, what makes this method non-invasive and safe for the donor. Hereby, it implements an evaluation of the drug effects in cells, in which the lack of a given protein causes the targeted pathological alterations. Up to now, wide variety of disease-specific hiPSCs were generated for modelling of numerous heart-related conditions, such as long QT syndrome $[76,80,126,153]$, familial dilated cardiomyopathy [176, 191], or arrhythmogenic right ventricular cardiomyopathy $[29,51,86]$. Additionally, recent developments in the field of hiPSCs research highlights the importance of using socalled isogenic cell lines, which are obtained with a use of CRISPR/Cas9 system by introducing mutations into control (healthy) cells or repairing mutations in patient-derived hiPSCs, hence all observed differences between control and mutated cells can be attributed to the mutation-of-interest, as the genetic background is identical.

The first investigations of drugs effects in hiPSC-derived cardiomyocytes considered them to have characteristic features of cardiomyocytes and confirmed functionality of cardiac ion channels [178]. Furthermore, these studies proved that they respond in a similar manner to ion channel-specific inhibitors as native cardiomyocytes. Similarly, Shinozawa et al. showed, that treatment with moxifloxacin, QT-prolongation inducer, triggers comparable FPD and echocardiography (ECG) traces in hiPSCCMs and healthy individuals, respectively [169].

The vast majority of drugs already authorized for sale or at the final stages of clinical evaluation are being withdrawn due to induced pro-arrhythmic effects $[37,67,90,143]$. Consequently, a great deal of emphasis is currently placed on thorough preclinical testing of drugs to exclude chemical compounds with such effect. Usually, the arrhythmia in hiPSC-CMs is demonstrated by the presence of TdP and QT prolongation. Due to the facts that there is a plenty of drugs that increase the risk of arrhythmias and their verification is carried out on a very wide scale, in 2013 the work began to establish the Comprehensive in Vitro Proarrhythmia Assay (CiPA) system [158]. This approach uses multidisciplinary drug evaluation in four components: assessment of multiple cardiac ion channels activity upon drug administration, in silico reconstruction of electrophysiological effects, confirmation of predicted effects in vitro on myocytes and clinical evaluation of potential effects [35]. Extensive studies 
provided by consortium working within this project showed that hiPSC-CMs respond accurately, constantly and concentration-dependently to selected drugs with clinically known pro-arrhythmic effect, indicating them as a good in vitro model for validation of pharmaceutical agents [20, 124]. Parallel validation performed by Kanda et al. [84] with a use of the Japan iPS Cardiac Safety Assessment (JiCSA) protocol confirmed the utility of hiPSC-CMs and MEA measurements in this field.

Interestingly, Ping Liang and co-workers investigated the drug response in hiPSC-derived cardiomyocytes generated from patients with various heart diseases of genetic origin [106], such as familial dilated cardiomyopathy, hereditary long QT syndrome and familial hypertrophic cardiomyopathy. The authors observed distinct, disease phenotypedependent electrophysiological outcomes following a stimulation with given compounds, what underlies necessity of drug validation on specific disease models. Currently, many groups develop the specific hiPSC-based models of diseaseof-interest and confirm their characteristic electrophysiological features at baseline [106, 113], suggesting, that they reflect accurately the investigated mechanisms.

Maizels et al. provided further evidence, that the consequences of the drug treatment detected in vitro with a use of hiPSC-CMs carrying the mutation-of-interest can be translated into clinical outcomes [113]. In their studies concerning catecholaminergic polymorphic ventricular tachycardia type 2 (CPVT2) caused by mutations in CASQ2 gene they revealed that pro-arrhythmic effect of labetalol and antiarrhythmic effect of flecainide in patient-specific hiPSCCMs correlates with clinical data collected from the same cell donor patient.

In more recent studies, Knottnerus et al. [88] introduced the hiPSCs from patients with very long-chain acyl-CoA dehydrogenase deficiency (VLCADD), who present lifethreatening arrhythmias. After differentiation of hiPSCs into cardiomyocytes, electrophysiological analyses were performed that revealed shortened action potentials, delayed after depolarizations and increased calcium ions concentration. However, it was proved that the use of chemicals reducing accumulation of long-chain fatty acid oxidation intermediates, such as resveratrol and etomoxir, resulted in reversion of these abnormalities and restoration of the correct phenotype, suggesting the possible use of these compounds in the therapy of VLCADD patients [88].

Experiments concerning Duchenne muscular dystrophy (DMD), rare genetic disorder caused by the mutations in $D M D$ gene and total lack of dystrophin protein, manifested by progressive muscle weakness and accompanying cardiomyopathy (for a review, see Loboda and Dulak [111]), demonstrated increased arrhythmic events rate in DMD hiPSC$\mathrm{CMs}$ in comparison to isogenic control [83]. Stimulation with propranolol, known beta-blocker, alleviates those effects (also in vivo), suggesting it as a potential clinical treatment for patients developing DMD-associated cardiomyopathy.

An increasing number of studies have found that cancer treatment may lead to unintended side effects causing irreversible heart damage and subsequent heart failure (reviewed by Lenneman and Sawyer [98]). In particular, four classes of cancer drugs were attributed to induce the cardiac complications in oncologic patients: anthracyclines, vascular endothelial growth factor (VEGF)-, human epidermal growth factor receptor 2 (HER2)-, and tyrosine kinase (TK)-targeted inhibitors (including monoclonal antibodies). On the molecular level, their cardiotoxic effects origin predominantly from induction of oxidative stress and subsequent increased production of free radicals, which results in mitochondrial dysfunction, DNA damage, cell apoptosis, and electrophysiological disturbances (for review, see Magdy et al. [112] and Sayed et al. [162]), which clinically are manifested principally by myocardial dysfunction (decreased ejection fraction), ischemic ECG changes, bradycardia, tachycardia, arrhythmia, and hypertension [[166], for a review see: [49, 174, 180]].

In the last few years, much more reports on use of hiPSC$\mathrm{CMs}$ in the field of so-called cardio-oncology have became available. They demonstrated that hiPSC-CMs responded to the treatment with known cardiotoxic compounds, adequately to previously observed clinical effects, while allowing to investigate the molecular mechanisms underlying those observations or testing combination of agents in order to establish an accurate cardioprotection. For instance, very comprehensive data provided by Chaudhari et al. and Knowles et al. showed transcriptomic differences in hiPSC-CMs treated with a range of doxorubicin concentrations, related to DNA damage and metabolic processes, allowing prediction of genetic variants determining the cardiotoxic responses magnitude and proved a drug-induced reduced splicing fidelity [31, 89]. Holmgren et al. extended the investigation of doxorubicinstimulated hiPSC-CMs to proteomics and microRNA transcriptomics (together with RNA sequencing) analysis and found the significant changes in expression profile at all examined levels pointing to the likelihood that a wide range of cell mechanisms in the heart can be influenced by doxorubicin [71].

As proposed by Burridge et al., hiPSCs generated from oncologic patient's somatic cells and differentiated into cardiomyocytes may provide an information about individual tolerance of proposed chemotherapeutic agents and support the adequate and safe dose selection [23]. RNA sequencing of hiPSC-cardiomyocytes obtained from 45 donors revealed transcriptional changes in response to the treatment with a range of doxorubicin concentration underlying the individual susceptibility to negative effects of doxorubicin [89].

Remarkably, Sharma et al. in their drug research studies utilized also other cell types present in the heart — cardiac fibroblasts and endothelial cells [168], likewise generated 
from hiPSCs. They aimed to validate the toxicity of known tyrosine kinase inhibitors (TKIs) approved for cancer treatment through both electrophysiological and gene expression analyses in order to create a safety assessment system. Interestingly, they reached a conclusion that one of the TKIs group inhibiting VEGFR2/PDGFR induced a high level of toxicity in all studied cardiac cell types; however, this effect can be diminished by upregulation of insulin/IGF signaling [168]. It is worth stressing, that the cardiac fibroblasts are the only one cardiac cell type, which can provide a considerable insight into the mechanisms of drug-induced cardiac fibrosis and evaluation of agents with potential anti-fibrotic activity. Established protocols [64] of their obtaining from hiPSCs allow to utilize the powerful methodology of patient- and disease-specific hiPSCs for modelling of drug response in terms of the disease of interest. Similarly, the primary cardiac fibroblasts can be purchased from various companies and cell banks. Palano et al. established the platform to test the candidate drugs in terms of their anti-fibrotic effects [136].

Most of the commonly used protocols primarily generate ventricular cardiomyocytes, however, protocols modifications enable obtaining of other cardiac cell types present in the heart-atrial cardiomyocytes [40, 46] and sinoatrial node-like pacemaker cells $[145,165]$. All of those subtypes possess welldefined, noticeably varied electrophysiological properties and gene expression profile (reviewed by Devalla and Passier [45] and Zhao et al. [203]), as it was assessed by patch-clamp technology [131], single-cell RNA sequencing [19], and voltage and calcium imaging [40]. Those differences arise from the presence of subtype-specific ion channels, and of note, pathology of some diseases is manifested in other than ventricular cardiac cells important in the context of pharmacological studies, since it has been shown that some drug-induced proarrhythmic effects are pronounced exclusively in one subtype, while they are not detectable in another one [40, 167].

On the other hand, maturation state of hiPSC-derived cardiomyocytes raises many questions whether they can accurately reflect the drug-induced effects. In fact, the immature phenotype of hiPSC-CMs, represented in general by structural disorganization, metabolism based on glucose or lactate instead of fatty acids and inconsistent ion channel kinetics impacts features of electrophysiological parameters (revieved by Mummery et al. [129], Denning et al. [43] and Karbassi et al. [85]). It has been proven that those dissimilarities may prompt the variant effects observed after treatment with a given compound (for reviews see: [60, 203]). Importantly, da Rocha et al. [154] noted an inconsistency in hERG channel activity between the immature and mature hiPSC-CMs in response to known pro-arrhythmic drugs, resulting in changes in action potential parameters. Furthermore, as reported earlier [131], hiPSC-derived cardiomyocytes display distinct gene expression profile associated with multiple ion channels variants. Well-documented discrepancies in the effect of clinically known compounds observed in hiPSC-cardiomyocytes raises a question regarding the accuracy of hiPSC-CM-based studies translation [2].

Immature phenotype, discussed in more details later, is a crucial disadvantage of hiPSC-CMs, affecting their structural, electrophysiological, and metabolic characteristic (reviewed by Yang et al. [193] and Karbassi et al. [85]) and have led to the development of procedures enabling enhancement of maturation, such as long-term culture [82, 94], electrical stimulation $[95,133,156]$ or more recent maturation media with fatty acid supplementation [54, 72], application of small molecules [110] and identification of cell surface markers [142]. For detailed reviews on this topic, see Zhao et al. 2020, Karbassi et al. 2020 and Li et al. 2020 [85, 103, 203].

\section{Two-dimensional vs. three-dimensional cultures/organoids}

While maintaining all the benefits of the hiPSCcardiomyocytes associated with patient- and disease-specific phenotype, the three-dimensional cultures introduce more physiologically relevant in vitro model resembling miniature organ (Fig. 3a). Within such structures, the cells adhere tightly to each other and form connections that allow signal transmission. As it was previously reported, also in case of human embryonic stem cells (hESC)-derived cardiomyocytes [21, $36,101,197]$, this approach has the advantage, that hiPSCCMs achieve adult phenotypic maturity, described predominantly by organized sarcomere structure (presence of $\mathrm{H}$ zones, I bands and $\mathrm{M}$ lines), electrophysiological features (typical action potential shape and related quantitative parameters), characteristic gene expression (increased MYH7/MYH6 ratio, increased SERCA2 and KCNJ2 level), and metabolic substrate alteration from glucose or lactate to fatty acids. Maturation level can be promoted by combining of threedimensional cultures with other methods, such as electrical stimulation [53, 133, 156], architectural cues [100, 133], mechanical stretch $[3,8,156,198]$, or co-culture with noncardiac cells $[185,198]$. This issue is particularly important for modelling of heart diseases, which usually appears in adulthood or adolescence and the electrophysiological response induced by adrenergic receptors or ion channel modulators may vary depending on the degree of cardiomyocyte maturity. For instance, Fong et al. [55] utilized the extracellular matrix powder (ECM) obtained from lyophilized decellularized bovine adult and fetal heart tissues as an environment for three-dimensional culture of hiPSC-derived cardiomyocytes. The stimulation with isoproterenol and propranolol, well known beta-adrenergic modulators (agonist and antagonist, respectively), resulted in stronger responses in 3D structures in comparison to their two-dimensional 
Fig. 3 hiPSC-derived cardiomyocytes growing in a a spheroid (cells were immunofluorescently stained for troponin I (red) and actin (green); nuclei were stained with $4^{\prime} 6$ diamidino-2-phenylindole (DAPI)) and in b co-culture with hiPSC-derived endothelial cells within ibidi $\mu$-slide after $24 \mathrm{~h}$ of shear stress (cells were immunofluorescently stained for troponin I (green) (a marker of cardiomyocytes) and VEcadherin (red) (a marker of endothelial cells); nuclei were stained with DAPI)

\section{a}

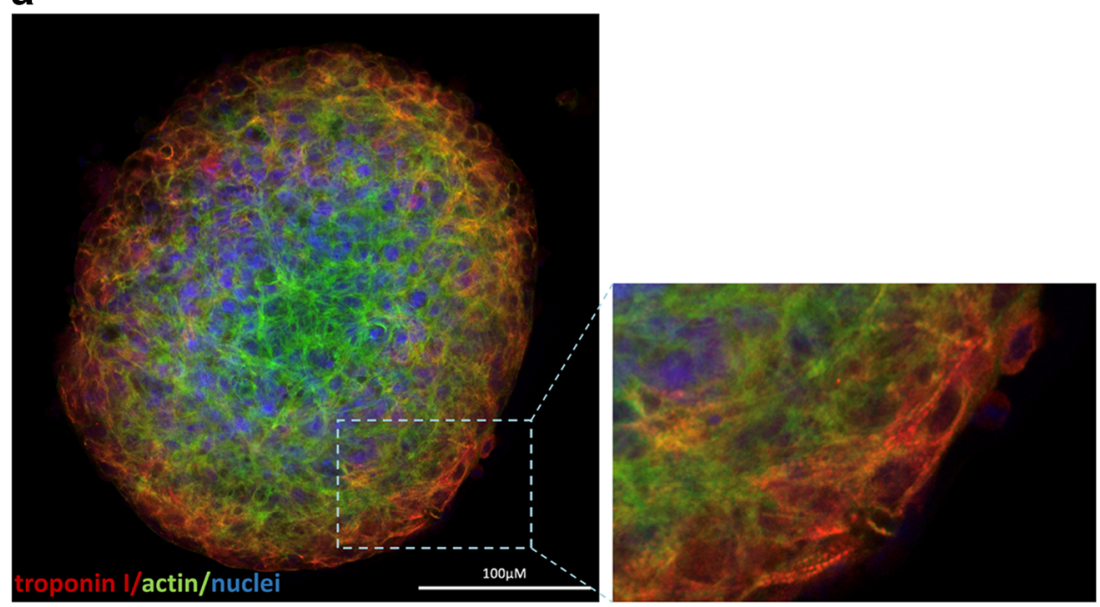

b

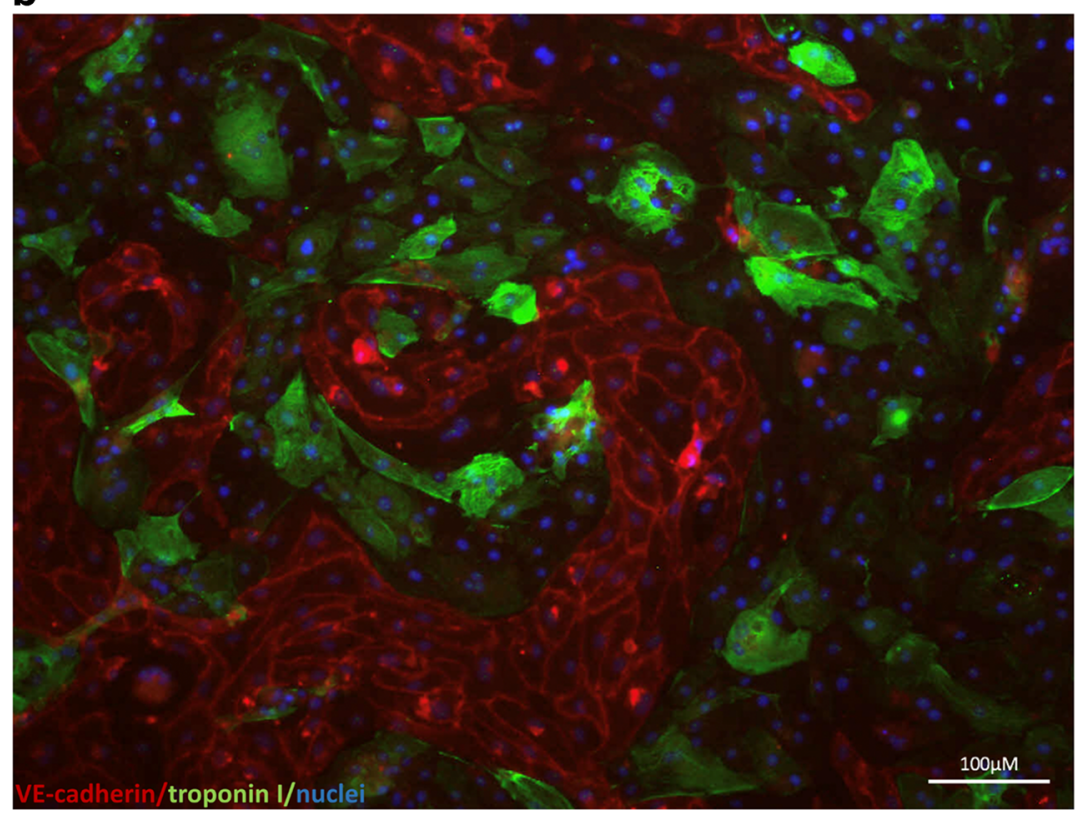

counterparts. This observation, together with higher levels of calcium handling proteins and higher expression of maturation-related genes suggest that increased cardiomyocyte maturation may influence the effect induced by pharmaceuticals.

Three-dimensional cardiac microtissues can be established by aggregation of hiPSC-cardiomyocytes, alone or together with other cell types in defined proportion (typically noncardiac cell types present in heart - endothelial cells, cardiac fibroblasts, and smooth muscle cells) through non-adhesive U-shaped wells, hanging drops or agitation culture. There are two methods of 3D structures formation (Fig. 4.) - scaffold-free, in which cells are seeded simply in culture medium or scaffold-based, which utilizes encapsulation of cells in medium enriched in ECM/hydrogels (such as collagen or Matrigel ${ }^{\circledR}$ ) or highly viscous chemical agents (such as methylcellulose, polyvinyl alcohol, etc.) and more complex engineering methods described more detailed in later sections. An alternative approach uses cardiac differentiation through embryoid bodies and the resulting contracting structures are referred as organoids. Although this solution is interesting, as it provides the complex mixture of cardiac lineage-specific cells, it suffers from lack of reproducibility, as the percentage of differentiated cardiomyocytes within each EB may vary and is difficult to estimate (for a review see Mummery et al. [129]). Importantly, three-dimensional models of cardiac cultures are not always spherical - there are longitudinal, cylindrical, ring-shaped or anchored structures, often referred as engineered heart tissue (EHT) [56, 59, 114]. It is worth mentioning here that the scientific nomenclature of organoids is not unanimous. The original definition of organoids concerned structures resulting from the differentiation of stem cells (hiPSCs and hESCs) or progenitor cells through embryoid bodies in a way that mimics the physiological formation of 
Fig. 4 Methods of 3D hiPSCCM-based structure formation
3D HIPSC-CMS-BASED STRUCTURES FORMATION METHODS

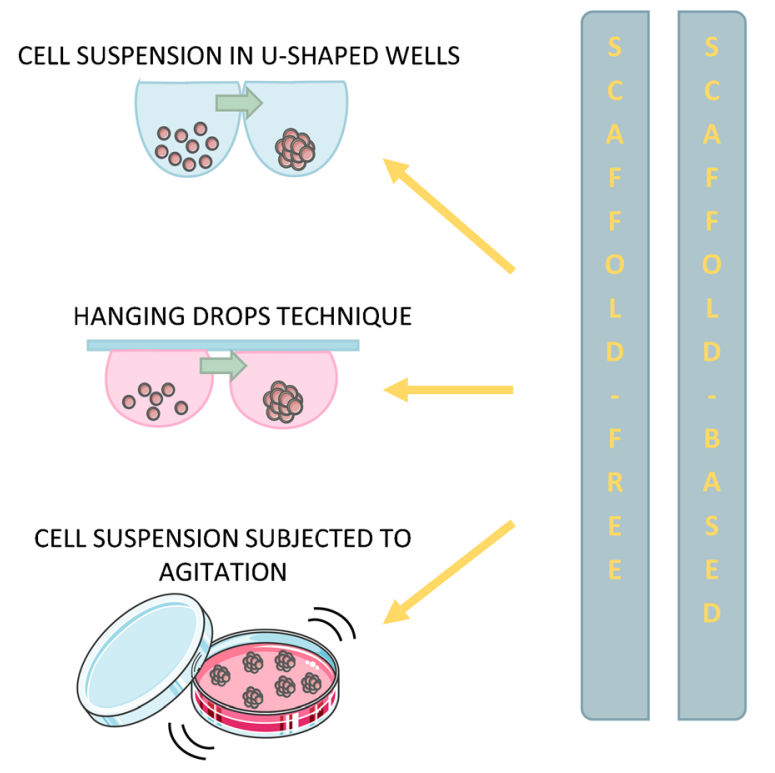

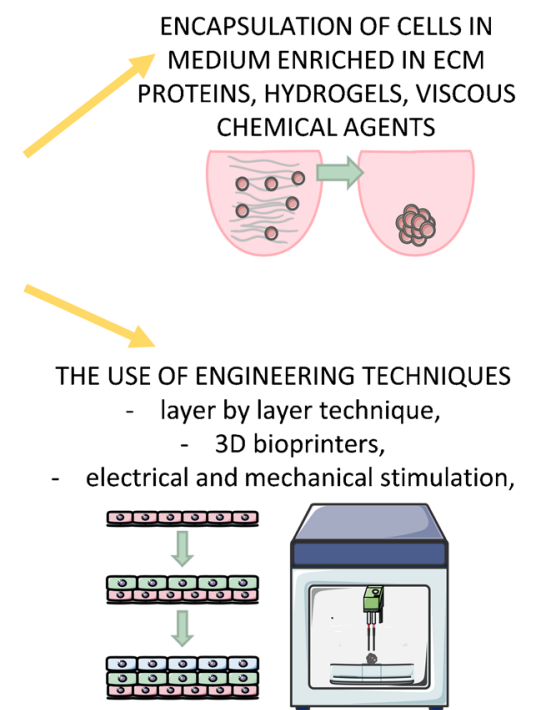

organs. Nowadays, many authors also refer to structures made of already differentiated cells mixed in defined proportions or the tissue explants, which, in our opinion, it would be safer and clearer to name "microtissues" or "spheroids."

Organoids and engineered heart tissues provide considerable number of properties resembling the native heart tissue, thereby ensuring the high quality of results based on their characterization. Cardiomyocytes, often in combination with the aforementioned other non-cardiac cells, form aligned syncytium with close cell-cell and cell-ECM connections. It is characterized by higher connexin-43 level and stronger electromechanical signal conduction ([57], reviewed by Guo and $\mathrm{Pu}$ [63]). In fact, non-cardiomyocytes numerically account for $70-80 \%$ of human heart $([14,141]$ reviewed by Guo and $\mathrm{Pu}$ [63]) and they form electrical and mechanical connections; therefore, their presence is essential for proper signal conduction. Moreover, extracellular matrix produced abundantly by fibroblasts improves the physiological stiffness and compactness, while endothelial and smooth muscle cells provide a microvasculature within the $3 \mathrm{D}$ cardiac structures [56]. In such a system, the effect of paracrine signaling induced by non-cardiomyocytes can be examined, together with other cardiomyocytes-non-cardiomyocytes interactions, as this significant side of native myocardial environment is missed in monocultures [57].

Very extensive research performed by Giacomelli et al. on cardiac microtissues formed from cardiomyocytes and noncardiomyocytes at different proportions demonstrated that both the endothelial cells and cardiac fibroblasts support the maturation of cardiomyocytes [57]. Interestingly, the authors also proved that the cardiomyocytes are not the only cells affected in heart diseases. In order to investigate it, they generated cardiac fibroblasts by differentiation of hiPSCs obtained from patient with arrhythmogenic cardiomyopathy carrying a mutation in PKP2 gene encoding plakophilin 2 protein, which is expressed in desmosomes. Cardiac 3D structures containing patient-specific cardiac fibroblasts had an impaired response to electrical stimulation and displayed arrhythmic events in comparison to structures containing control cardiac fibroblasts. Additionally, higher proportion of alpha-SMA-positive epicardial cells and cardiac fibroblasts in this experimental group suggest that they possess a higher tendency to form the fibrotic tissue and impair the electrical conduction in heart [57].

Assessment of electrophysiological function of cardiomyocytes cultures in two-dimensional versus threedimensional system measured with a use of patch-clamp technique showed dissimilar action potential-related parameters, such as higher action potential amplitude, lower resting membrane potential, and higher maximum upstroke velocity in monolayer-cultured CMs. Of note, some of the electrophysiological parameters can be also influenced by a size of $3 \mathrm{D}$ structures; therefore, maintaining of equivalent protocols for their formation is crucial for the credibility of the obtained results [13]. Moreover, these and other [7] studies showed that the effect of stimulation with known cardiotoxic drug doxorubicin are more pronounced in two-dimensional in comparison to three-dimensional cultures, suggesting the apparently stronger response activation, while the observed abnormalities are more variable at the same time.

Importantly, Beauchamp et al. demonstrated that co-culture of cardiomyocytes and cardiac fibroblasts in spheroids, obtained via hanging drops or non-adhesive wells, is prominently more authentic for the latter cell type, as the lower number 
of activated fibroblasts (myofibroblasts) was detected in comparison to 2D cultures [13]. Rigid environment of monolayer culture is most likely factor evoking an intensified transdifferentiation of fibroblasts to myofibroblasts. Thereupon, they possess other mechanical and biochemical properties, and importantly, their paracrine effect may be distinct from that of fibroblasts cultured in 3D environment having physiological stiffness. Consequently, they can differently affect the cardiomyocytes and their responses, for instance by slowing the spontaneous contraction rate in two-dimensional co-cultures [13].

The introduction of engineering methods into biological research is a promising tool for modulating the properties of the obtained 3D structures to reflect the conditions of the heart. Selection of suitable hydrogels allows to mimic the physiological cardiac tissue stiffness and creates a scaffold for cell arrangement. Such approach implements the genuine structural, mechanical, and conductive properties that reliably reflect the contractility of native cardiac tissue. Both natural proteins (fibrin, collagen, matrigel) and synthetic polymers (polycaprolactone, polyethylen glycol) are commonly used for cardiac three-dimensional structure engineering. In addition, it has been repeatedly demonstrated that cardiac engineered tissues embedded in ECM or other hydrogels show higher viability [130], which is most likely associated with maintaining close connections between cells and preventing anoikis-type cell death.

In order to maintain the close contact between cells and preserve primary cell-cell and cell-ECM junctions, the socalled layer by layer technique is used. In this case, 3D structures are assembled from cardiomyocytes sheets obtained from $2 \mathrm{D}$ cultures placed one on another. Introduction of cardiac fibroblasts and cardiac microvascular endothelial cells into the 3D hiPSC-CMs tissue together with fibronectin and collagen coating provided formation of blood capillary networks [7]. Further improvement of this technology attempted to introduce the microvascularization into the cell patches. Schaefer et al. established a bi-layered construction composed of hiPSC-CMs sheet and aligned patch of both pericytes and endothelial cells [163]. These studies highlighted the superiority of this assembly mimicking the native tissue, as the bilayered structures exhibited higher viability, maturation state, and stronger contraction force in comparison to the monolayered only cardiac counterparts.

Providing the heart-specific structure for in vitro studies can be challenging; however, it becomes feasible due to the increasingly common and available use of 3D bioprinters. This method enables the construction of tissues with respectively designed organization in a controlled and precise manner and thus represents an innovative alternative to randomly assembled three-dimensional structures. The bioprinting methodology usually combines the employment of cells, extracellular matrix proteins and biomaterials to construct the tissue with given organization and parameters. Fabrication of 3D tissues can be accomplished by orientation-controlled assembly of different types of cells precoated with ECM proteins nanofilms [184]. Such heart-specific structure exhibited organized cells alignment, as well as more synchronized and higher contraction rate. Ong et al. proposed cardiac patches prepared with a use of bioprinting in order to assemble cardiac structures formed from hiPSC-CMs in combinations with fibroblasts and endothelial cells [135]. Those structures exhibited presence of connexin-43, a gap junction protein triggering better electrical conduction properties, and marks of vascularization. Three general bioprinting methods are available, differing in an approach, price, and velocity (reviewed by Puluca et al. [146]); however, this field in the context of hiPSCcardiomyocytes is relatively novel and data related to its utility in drug research is limited, therefore further improvement and evaluation is needed.

The engineering methods are also a fundamental solution for anisotropy in hiPSC-CMs in vitro culture. Proper, unidirectional alignment of cells within the tissue is essential for the compatible excitation-contraction coupling within the studied structure and authenticity of pharmaceutically generated responses. It can be typically ensured through electrical stimulation [68, 157, 179], mechanical loading and shear stress $[157,185]$ or architectural cues $[1,28,188]$.

Main disadvantage of 3D model lies in hypoxia condition present in the central part of the structure, as most of the in vitro model still usually lacks the vascularization; therefore, the lack of oxygen and nutrient supply prompts the formation of so-called necrotic core. This issue can be partially solved by formation of small size structures/organoids or development of vascularization, likely in models consisting of other noncardiac cell types, as discussed above.

\section{Overview of heart-on-a-chip systems}

Organs-on-a-chip have recently become an increasingly popular technological tool. Their innovativeness lies in the use of engineering inventions to recreate physiological conditions in which the organ is located. This field is relatively new; however, there are already companies which produce such tools commercially to adapt them for the need of a given model or experiment (e.g., ibidi, Mimetas, BeOnChip) (Fig. 3b).

A great deal of attempts related to heart-on-a-chip technology was focused on improvement of maturity state of stem cell-derived cardiomyocytes. This has led authors such as Nunes, Marsano, and Zhao to investigate the designs of devices with specific properties and additional implements, such as architectural cues, electrical and mechanical stimulation or shear stress [116, 133, 192], and evaluation of maturation markers in cardiomyocytes cultured within such chips. 
Heart-on-a-chip technology represents a valuable and useful alternative to previously described models, as it provides automated control of culture conditions, such as medium oxygenation (exchange between normoxia and hypoxia) $[108$, $117,128,175]$, pH level [128], shear stress with specified culture medium flow rate $[164,186]$, temperature control, and electrical or mechanical stimulation. However, the main advantage of heart-on-a-chip models is continuous monitoring and measurements of cell physiological responses, which is enabled by use of built-in readouts, sensors, and electrodes.

A growing body of literature has reported a development of new heart-on-a-chip devices enhanced by the possibility of simultaneous measurement of parameters during the culture (Table 1 summarizes heart-on-a-chip systems based on hiPSC-CMs described in the last 5 years). One of them was designed by Agarwal et al. who introduced so called muscular thin films (MTF) for measurement of contractions [5]. Additionally, cells can be stimulated electrically and through the shear stress and the proper functioning of MTF technology was confirmed by measurement of changes in contraction frequency after stimulation of rat cardiac muscle cells with isoproterenol [5]. More recently, Sakamiya et al. introduced the micro-pillar assay-based contraction parameters measurement of engineered cardiac tissue growing within the heart-on-achip enabling the online monitoring of recorded data [160]. The heart-on-a-chip design proposed by Sidorov et al. combines the possibility of electrical stimulation with continuous sensing of contraction force by magnetically actuated microcantilevers and electrophysiological properties with a use of micropipettes intended for analysis of moving object, such as contracting tissues [171].

Combining of $3 \mathrm{D}$ printing together with the culture inside microfluidic device was proposed in 2016 by Zhang et al. [200]. Using this approach, the authors fabricated structured endothelial cell-based skeleton filled with hiPSCcardiomyocytes and placed into perfusable microfluidic bioreactor. As a consequence, the cardiac tissue construct with high cellular organization was obtained and the culture under the medium flow provided the nutrients and normal oxygen concentration across whole tissue, thereby increasing cell viability. Stimulation with doxorubicin revealed the predicted physiological contraction rate impairment [200].

Another microfluidic device was designed in order to enable the common culture of hiPSC-derived cardiomyocytes and endothelial cells within one device in such a way that hiPSC-CMs grow in 3D matrix in the central part of the chip and hiPSC-derived endothelial cells are seeded into two lateral channels (connected with middle channel by small apertures) with continuous medium flow mimicking the microvasculature-like flow [52]. After 7 days of cell culture, the authors confirmed the proper phenotype of both cell types, their viability and formation of capillary-like structures formed from endothelial cells and reaching the channel containing cardiac tissue, what supported the idea of microvasculature formation within the heart-on-a-chip system.

Many researchers have addressed the issue of hypoxia present in the inner part of the three-dimensional structures attempting to introduce the channels in microfluidic devices enabling the delivery of fresh medium. Up to now, various approaches and designs have been proposed. One of them was fabrication of central channel containing cells and two lateral channels for the medium supply [118]. Pharmacological compounds can be delivered through those channels and as the chamber containing cells is transparent their direct effect on, i.e., beating rate can be observed with a use of optical imaging. Additionally, heart-on-a-chip technology enables also the studies of chemical compounds concentration gradients. Marsano et al. established similar microfluidic device enabling the medium flow through the side channels [116]. However, in this design, after placement into the chip, the hiPSC-cardiomyocytes are aligned into the chamber of a given geometry and subjected to pressure-loaded mechanical stretch to provide the designed organization of cells within the construct and markedly improved maturation features and cell-cell junctions.

More advanced approach proposed by Zhao et al. who developed the platform for common culture of atrial and ventricular cardiomyocytes placed at opposite ends of so called heteropolar biowire [202]. The device enabled the electric stimulation, which has been found to improve the maturation of cardiac cells. Additionally, it provided continuous screening of force parameters and electrophysiological responses and demonstrated the chamber-specific effects of known pharmacological agents [202].

It should be emphasized that organ-on-a-chip systems are largely constructed by engineers; therefore, their use in a biomedical laboratory often requires advanced skills. To address this issue, Schneider et al. [164] designed a device with customized centrifugal loading system enabling even distribution of cells. It consists of a chip mounted on a microscope slide and a pipette tip containing cells inserted inside, which is subsequently centrifuged. Hereby, homogeneous and invariable for all experiments microtissue is obtained in a standardized and effortless manner. This method prevents also formation of air bubbles inside, which is a frequently reported problem [18].

In 2014, Wang et al. utilized the heart-on-a-chip technology in order to characterize the abnormalities present in cardiomyocytes obtained from hiPSCs generated from somatic cells of Barth Syndrome patient [187]. The disease is caused by mutation in gene encoding tafazzin protein located in mitochondria and leads to dilated cardiomyopathy usually diagnosed shortly after birth. In those studies, hiPSC-CMs were characterized in terms of metabolic phenotype and mitochondrial activity, and in the next step, they were seeded onto 


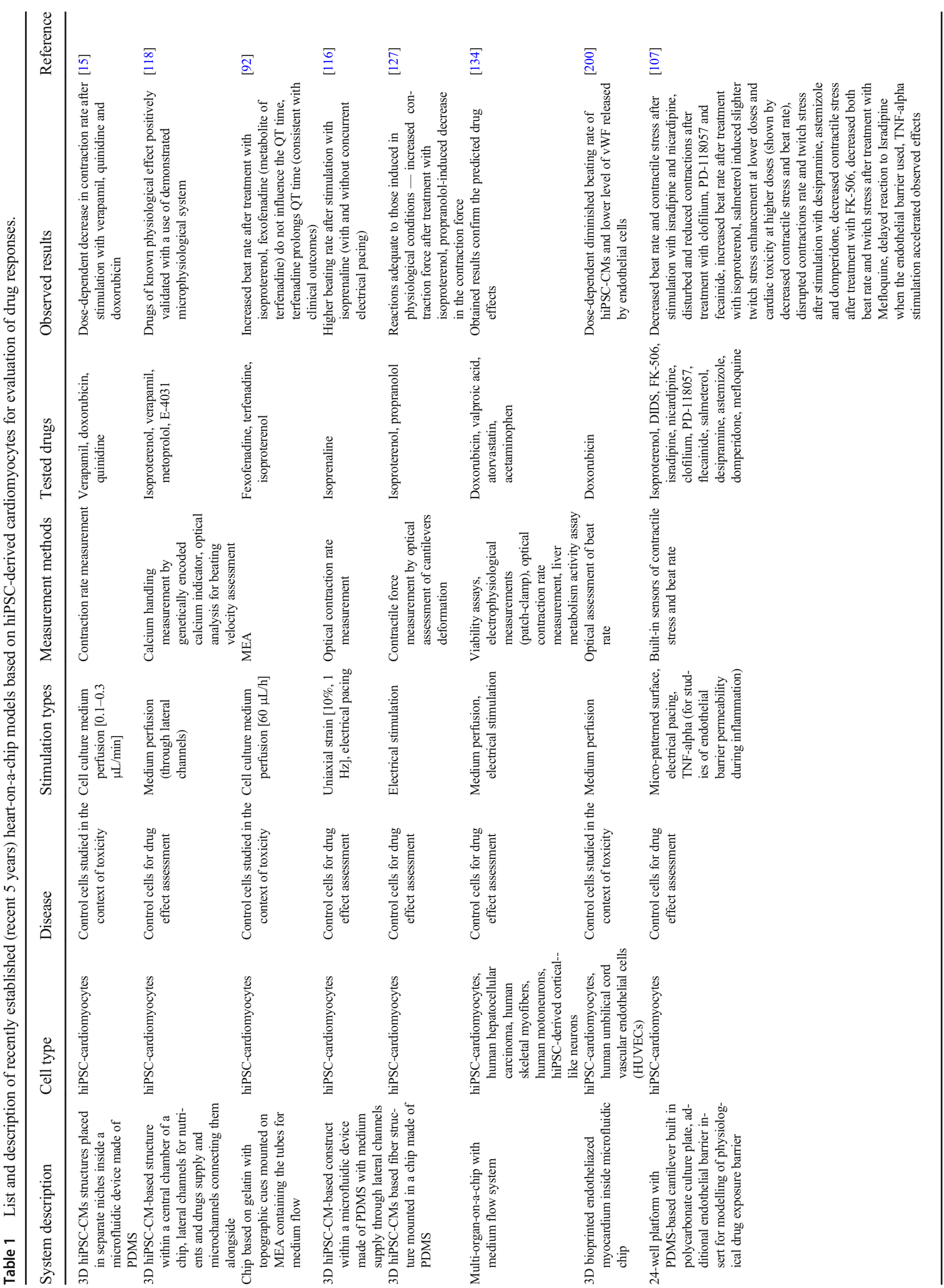




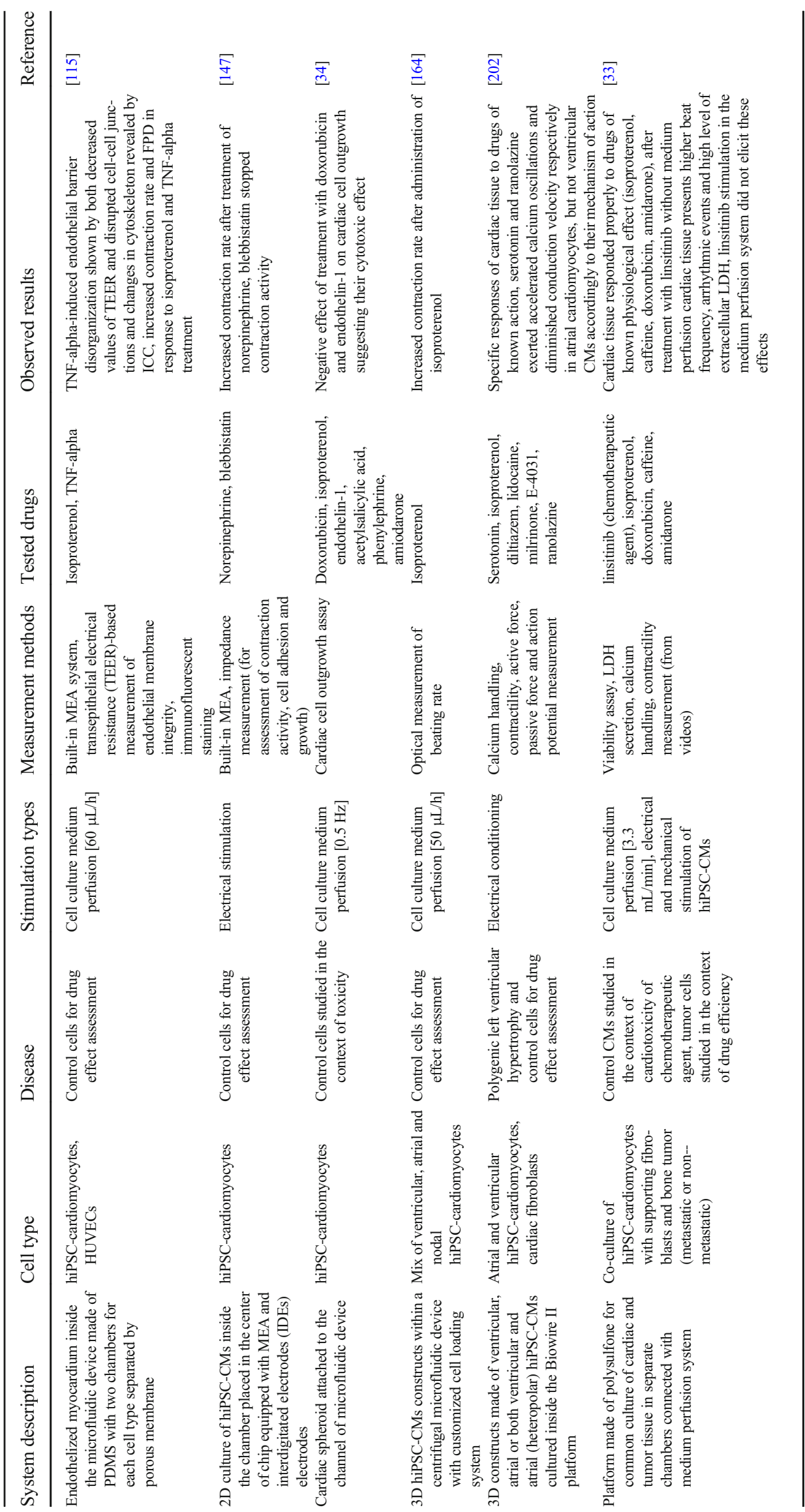


MTFs and combined with a engineered platform in order to create the organ-on-a-chip system for determination of contractility of control versus disease-specific cardiomyocytes [187]. Furthermore, the heart-on-a-chip system enabled verification of potentially therapeutic chemical agents by continuous monitoring of cell responses to small molecules [187].

Excellent studies performed by Chramiec et al. [33] demonstrated the utility of organs-on-a-chip technology in the field of cardio-oncology. They introduced a microfluidic device with separate chambers for the common culture of hiPSC-CMs and bone tumor cells with the possibility of shear stress application. In the initial phase, the characterization of hiPSC-CMs was performed by assessment of cell electrophysiological behavior in response to stimulation with drugs of known physiological effect, e.g., isoproterenol, doxorubicin, etc. Further research was focused on chemotherapeutic agent called linsitinib with uncertain clinical effect. In the first stage, the drug was delivered to both tissues in mixed media (for both types of cells) without the perfusion system and the cytotoxicity of tumor cells was clearly visible, while only slight changes in electrophysiological profile of cardiac tissue (indicating arrhythmias) was observed. Interestingly, when the medium perfusion was applied, the cytotoxic effects of linsitinib were no longer observed. It is worth stressing that the engineered microfluidic form of the cell culture allows the recapitulation of clinical outcomes observed in patients involved in the clinical trials. The first analysis carried out in laboratory conditions showed a promising antitumor effect, while after administration of the drug to patients, such effects were not observed. Summarizing the above, linsitinib did not elicit any significant changes in calcium oscillations profile nor the cytotoxicity (measured by LDH secretion), while it induced some arrhythmic events; however, at the relatively low level [33], it is consistent with the clinical trial data.

It is worth noting that in recent years, more and more innovative heart-on-a-chip technology projects have been created. One of the most interesting approach utilizes common culture of cardiomyocytes and neuronal cells in order to observe the effect of neuronal activation on functioning of cardiac cells as well as other interactions between those cells [26, 159]. Oleaga et al. developed a platform for combined culture of four cell types representing four different organs - heart, skeletal muscle, brain, and liver [134]. It was utilized to perform the toxicity studies with five drugs of known effect and obtained results were compared. Both the viability data and electrophysiological analysis confirmed the predicted activity of the drugs, validating the system for further drug-related research. Sakai et al., in turn, demonstrated that hiPSC-CMs beating rate can be controlled by rat sympathetic neurons when cultured in separate chambers connected by microchannels (enabling growing neurons' axons to pass through) [159]. This field is relatively new, and most of the available data are based on cells of animal origin; therefore, they are beyond the scope of this paper.
More studies on drug activity in hiPSC-derived neuro-cardiac organs-on-a-chip models are awaited to better understand the interactions in this axis.

In the light of solutions and approaches outlined in this chapter, it can be seen that this area of research, although new, is constantly evolving. Within the next years, heart-ona-chip technology is likely to become an important component of preliminary drug development research. However, further evaluation of the system is necessary in order to provide the highest credibility in relation to properties of the native cardiac tissue. Very extended research described by Zhao et al. tested and established the best conditions for heart-on-a-chip culture with a use of Biowire II platform providing mature tissue with appropriate physiological properties, most similar to those prevailing in the human heart [192]. Most important observations emerging from this optimization process is that proper seeding density (defined as 50 million cells per $\mathrm{mL}$ ), slowly increasing electrical stimulation intensity ( $1 \mathrm{~Hz}$ per week) and right ratio of non-cardiomyocytes to cardiomyocytes (30\%:70\%) are considered as the most important for preparation of fully functional heart-on-a-chip system [192]. Also, the cardiac fibroblasts were indicated as more accurate representative of non-cardiomyocytes for in vitro cardiac tissue formation, as the other cell type-mesenchymal stromal cells (MSCs) - did not provide required electrical coupling with cardiomyocytes [192].

\section{Discussion}

Taken together, abovementioned studies point towards the idea of utilization of hiPSC-derived cardiomyocytes in drug research. Limited access to cardiac tissue biopsies and troublesome in vitro culture of primary cardiomyocytes advanced the idea of modeling of heart response on disease- or donorspecific cells. Significantly, for more general research, it is not required for every laboratory to reprogram the somatic cells to hiPSCs by their own. Both the control and disease-specific (also obtained by applying gene editing techniques) hiPSCs and hiPSC-derived cardiomyocytes are widely available, as they can be obtained from numerous companies or biobank core facilities, such as WiCell Research Institute, Coriell Institute for Medical Research and European Bank for Induced Pluripotent Stem Cells (EBiSC).

Limited access to cardiac tissue biopsies and primary cardiomyocytes advanced the idea of utilization of hiPSCderived cardiomyocytes, not only for drug research but also disease modelling. Well-established and widely used genetic engineering tools support this approach by giving a possibility of introduction of isogenic cell lines. Beside, this solution is also applicable in development and evaluation of novel class of drugs based on antisense oligonucleotides, such as Exondys 
$51 ®$ (Eteplirsen) for the treatment of Duchenne muscular dystrophy (DMD) [48, 199, 201].

Before entering the market, all drugs must be approved by Food and Drug Administration (FDA) in regard to USA or European Medicines Agency (EMA) in regard to Europe; however, in case of FDA, their exhaustive investigations become often determinants for the decisions worldwide. Major safety assay recommended by FDA is hERG assay, evaluating whether the potential chemical agent is prone to block the hERG channel triggering the arrhythmic events as a consequence [151]. The protocol usually utilizes HEK293 or Chinese hamster ovary $(\mathrm{CHO})$ cells stably transfected with hERG and it was shown that they can accurately recapitulate this cardiotoxic manifestation ([138], reviewed by Redfern et al. [150]). However, other observations affirmed that some of the evidence are not conclusive, as the responses can differ due to the fact that those models lack some of substantial human cardiomyocyte-specific ion channels. Moreover, some drugs (e.g., verapamil, pentobarbital, ranolazine) have been reported to block the hERG, but they are clinically safe in humans and its broad impact on other ion channels explains this phenomenon (reviewed by Redfern et al. [150] and Lester and Olbertz [99]).

Applying hiPSC-CMs for drug research purposes, it should be kept in mind that their immature status may influence to some extent the observed effects by impacting the excitationcontraction coupling. This is particularly important for studies of QT prolongation phenomenon, often being a side effect of tested drugs, as immature hiPSC-CMs exhibit alterations in initial QT interval duration; therefore, the attempts aiming to develop the scalable maturation state improvement methods are required. Zhao et al. reviewed the similarities and variations in drug response comparing immature hiPSCderived cardiomyocytes [203] and concluded that considerable number of pharmaceutical agents, such as isoproterenol or dofetilide exhibit distinct effects in hiPSC-CMs and adult CMs pointing towards the higher sensitivity of the former. On the other hand, those differences are mitigated when compared to matured hiPSC-CMs and such drugs as verapamil or diltiazem induce similar responses both in adult CMs and matured hiPSC-CMs [203].

Importantly, hiPSCs technology provides the opportunity to obtain the cardiomyocytes from distinct cardiac compartments. It is particularly advantageous for drug testing studies, as many drugs induce the effects through chamber-specific receptors or show chamber-specific toxicity [97, 167, 202]. Moreover, introduction of non-cardiac cells, such as endothelial cells or smooth muscle cells, enriches the methodology with vascularization arising within the engineered cardiac tissue. Although it does not exactly reflect the blood vessel system found in native tissue, at least to some extent, it enables to check how a given drug affects the cells involved in its delivery.
On the other hand, it should be emphasized that both generation of hiPSC-CMs and their culture for experimental purposes is fairly expensive. For this reason, from the point of view of large-scale experimental setups, reduction of cardiomyocyte number is more preferable.

A review of independent electrophysiological characteristics of cardiomyocytes in the literature showed significant disturbations in parameter values depending on the differentiation protocol or type of culture [50], which may be also evoked by the differing degree of maturity or proportion of cardiac subtypes in population of cells obtained as a result of differentiation process.

A crucial aspect of both scaffold-based three-dimensional structures and heart-on-a-chip approach is an accurate selection of the type of biomaterial. Primarily, it should possess all the features required for a given experimental design, thus the proper chemical (such as solubility or degradability) and mechanical characteristics (such as stiffness, pores size or strength). However, in the context of biological studies one of the most crucial factor is biocompatibility. In in vitro drug research models, it is referred to the general safety of the substrate and its metabolites, as well as inability to interact with cells and drugs. The ability to absorb small molecules, as it was described in case of polydimethylsiloxane (PDMS) [123], may interfere with drug action and affect the observed effects. Polymers and other biomaterials used for fabrication of chips should be additionally optically transparent and gaspermeable in order to visualize the cells behavior in long-term experiments. More advanced application of biomaterials involves the formation of architectural cues supporting the proper alignment of cells [183] and use of conductive and electroactive materials in order to improve the electrophysiological function of cardiac tissue [39, 173]. In case of 3D cardiac cultures employment of biomaterials to form a porous scaffold can solve the problem of hypoxia commonly found in scaffold-free 3D structures [122]. The above aspects of chip design indicate the need for close cooperation between biologists and engineers in order to obtain a tool with desirable features and applications while maintaining the appropriate physicochemical parameters.

The in vitro culture of several cell types within one chip requires the media to be selected in such a way that it is suitable for all cell types, as an inadequate media can lead to metabolic disturbances, abnormal cell growth, impaired proliferation, dedifferentiation or even cell death. Usually, the method of adapting the cells to a common medium before starting the experiment is used, but it is often challenging, so this aspect must be taken into account when preparing the experimental set up.

Given that hiPSC-CM-based drug evaluation is limited to assessment of acute effects on cellular level, it is expected that the multilevel data in the context of off-targets, metabolic interactions, or long-term effects is missed. This is especially 
important in the context of drug testing in the field of cardiooncology, because the treatment with some chemotherapeutic agents causes cardiotoxic effects even several years after the end of cure [93]. Therefore, it is very likely, that animal models will not be completely excluded from drug development research in the near future, due to the need of broadspectral validation of some compounds including whole organism and pharmacokinetics/pharmacodynamics examination; however, hiPSC-CM-based studies can be a bottleneck in the initial verification of drug libraries, thus limiting the number of animals used for this purpose, accordingly to the 3R strategy.

In parallel, recent advancement in bioinformatic tools allow for computational prediction of the behavior of the drug in silico. A huge library of available chemical compounds and their characteristics allows for the preliminary exclusion of drugs, e.g. of a pro-arrhythmic nature, thereby reducing the time and costs of unnecessary testing. Combination of in silico screening together with hiPSC-CM-based in vitro studies seems to be a promising approach towards enhancing our understanding of the mechanisms of drug action before releasing it to further stages of testing.

\section{Future perspectives}

Taken together, above findings suggest a very promising utilization of hiPSC-CMs technology in the field of drug research due to the possibility of compound validation in patient- and disease-specific model. Recently, heart-on-achip model is increasingly becoming a popular tool providing more physiological conditions for the tissue culture, while combining the mechanical and electrical stimulation, microenvironmental conditions control and continuous registration of multiple parameters at the same time in one device. However still, despite many scientific reports on this topic, the technology requires further technical improvements. Moreover, on account of the fact that cardiotoxicity often occurs simultaneously with other organ-specific toxicity, extended multi-organ-on-a-chip technology, also referred to as "body-on-a-chip," "human-on-a-chip," or "lab-on-a-chip" in the context of drug testing is an extremely encouraging idea. It implies a creation of the chip with separate chambers containing various miniorgans connected with each other in appropriate experimental setup in order to evaluate the drug effect taking into account its effect on other organs, such as liver, brain, or kidneys. It is feasible due to the presently established protocols of hiPSCs differentiation into other cell types such as hepatocytes or multiple neuron subtypes, as well as an easier access to human primary cells and tissue explants.

Moreover, very extensive research on utility of liver [62], kidney [44], and gastrointestinal [196] three-dimensional structures in drug toxicity studies put them as a model accurately reflecting the responses in native tissues. In the field of lab-ona-chip technology, a development of chips intended for nephrotoxicity ([77, 194], reviewed by Wilmer et al. [189] and Lee and Kim [96]), hepatoxicity ([78, 144], reviewed by Deng et al. [42] and Moradi et al. [125]), and neurotoxicity ([139, 148], reviewed by Bang et al. [11]) have been already reported in the literature. A potential negative impact or toxicity induced in other organs is a very important signal during preclinical studies of all drugs.

First attempts in terms of creating the multi-organs-on-achip technology were already reported. Independently, Choucha-Snouber et al. and Li et al. established common culture of kidney and liver cells in a microfluidic device in order to assess the effect of ifosmafide and verapamil metabolites produced in hepatocytes in nephrotoxicity [32, 104]. Using similar approach, Chang et al. performed the studies examining metabolism of aristolochic acid and its effects on toxicity induction in kidneys [30]. Future projects concerning the involvement of cardiac tissues cultured with other cell types will be of high interest for drug research purposes.

More recently, Rajan et al. [149] assembled highly advanced multi-organ microfluidic device consisting of liver, heart, lung, endothelium, brain, and testis 3D cultures. In this approach, the organoids were composed of several cell types present in a given organ, as well as organ-specific fibroblasts or endothelial cells, providing a very complex structures resembling native tissues. The authors validated the system through stimulation with drugs of known effect. One of them was capecitabine, which is not toxic by itself; however, its metabolite 5-fluorouracil, which is also used as chemotherapeutic agent, was identified as toxic for heart and lungs. Interestingly, it was demonstrated that stimulation with capecitabine induced the toxicity in heart and lungs organoids, as it was metabolized in liver miniorgan, while this effect was not seen when the liver construct was removed from the system [149]. This observation raises expectation, that the multi-organ in vitro models can accurately reflect the metabolism of drugs in organism and enable prediction of the multi-system effect.

\section{Conclusions}

Human-induced pluripotent stem cell-based in vitro models provide possibility of generating patient- and diseasespecific cell types without ethical concerns in contrast to human embryonic stem cells (hESCs), which also can be differentiated into cells of all three germ layers. hiPSCcardiomyocytes introduced a groundbreaking tool for drug effect and cardiotoxicity evaluation and currently attracting considerable interest in terms of chamber-specific drug evaluation. hiPSCs technology gives the opportunity to differentiate the patient-specific hiPSCs line into many types of cardiac and non-cardiac cells present in heart maintaining the same genetic background. The in vitro models consisting of 
multiple cardiac cell types better reflect the complexity of the human heart and represent a more advanced model for research.

Formation and advancement of three-dimensional cardiac organoids and tissues, as well as heart-on-a-chip technology received much attention in the past decade. Many efforts made in this field enabled the establishment of systems and technologies with improved physiological relevance, maturation state, and combined measurement methods. In fact, it was reported that $3 \mathrm{D}$ cardiac structures reflect more accurately the physiological phenotype and drug-induced responses in comparison to their $2 \mathrm{D}$ counterparts.

Nonetheless, hiPSC-CM-based in vitro studies do not fully correspond to conditions occurring in living organisms; therefore, neither the long-term effects nor pharmacokinetic profile can be assessed. Variety of metabolic processes occurring in living organisms may affect the drug potency; hence, the in vitro observations do not coincide with the clinically observed reactions. Taken together, hiPSC-CMs platform represents a powerful strategy for use in drug screening and evaluation of pharmaceutically induced cardiac toxicity; however, it should be aware of certain limitations, which have all currently available models. The future directions include the improvement of the three-dimensional system through better vasculature and new, intended for this model, research tools, as well as the development of a multi-organs-on-a-chip system. It reflects more closely physiological conditions and allows the assessment of investigational drugs not only in the context of a direct impact on cardiac tissue but also a simultaneous effect on other organs and checking the toxicity of metabolites of the studied drugs due to the presence of liver miniorgans.

As the preclinical drug research is fairly time-consuming and very expensive, hiPSC-CM-based technology allows for the preliminary evaluation of drug libraries and forwarding for further research the chemical compounds, which are potentially active and safe. In addition, due to the differences between animals and humans, it is possible to check human-specific responses after drug administration. Otherwise, some of the outcomes unrevealing in animals would become apparent only after administration to humans and be a serious threat to life.

Acknowledgements We thank dr Neli Kachamakova-Trojanowska for assistance with seeding of cells into Ibidi channel $\mu$-Slides and connection of the medium flow system. We thank dr Michał Sarna for assistance with confocal microscopy. Figures were designed using Servier Medical Art (https://smart.servier.com).

Code availability Not applicable.

Funding Research on the iPSC and iPSC-derived cells in the authors lab is supported by the following grants: MAESTRO (UMO-2018/30/A/ NZ3/00412) (JD), SONATA (UMO-2018/31/D/NZ3/02541) (JS), and PRELUDIUM (UMO-2019/33/N/NZ3/03064) (KA) from the National Science Centre, CISTEM MSCA RISE (Z/H2O/00023 from H2020 program: grant agreement no. 778354) (JD) and NMJ-on-a-chip (UMO-
2019/01/Y/NZ3/00012) (JD) from JPND initiative (Horizon 2020) and National Science Centre.

Data Availability Not applicable.

\section{Declarations}

Ethics approval Not applicable.

Consent to participate Not applicable.

Consent for publication The authors give consent to publish.

Conflict of interest The authors declare that they have no conflict of interest.

Open Access This article is licensed under a Creative Commons Attribution 4.0 International License, which permits use, sharing, adaptation, distribution and reproduction in any medium or format, as long as you give appropriate credit to the original author(s) and the source, provide a link to the Creative Commons licence, and indicate if changes were made. The images or other third party material in this article are included in the article's Creative Commons licence, unless indicated otherwise in a credit line to the material. If material is not included in the article's Creative Commons licence and your intended use is not permitted by statutory regulation or exceeds the permitted use, you will need to obtain permission directly from the copyright holder. To view a copy of this licence, visit http://creativecommons.org/licenses/by/4.0/.

\section{References}

1. Abadi PPSS, Garbern JC, Behzadi S, Hill MJ, Tresback JS, Heydari T, Ejtehadi MR, Ahmed N, Copley E, Aghaverdi H, Lee RT, Farokhzad OC, Mahmoudi M (2018) Engineering of Mature human induced pluripotent stem cell-derived cardiomyocytes using substrates with multiscale topography. Advanced Functional Materials 28:1707378. https://doi.org/10. 1002/adfm. 201707378

2. Abi-Gerges N, Pointon A, Oldman KL, Brown MR, Pilling MA, Sefton CE, Garside H, Pollard CE (2017) Assessment of extracellular field potential and $\mathrm{Ca} 2+$ transient signals for early QT/proarrhythmia detection using human induced pluripotent stem cellderived cardiomyocytes. J Pharmacol Toxicol Methods 83:1-15. https://doi.org/10.1016/j.vascn.2016.09.001

3. Abilez OJ, Tzatzalos E, Yang H, Zhao M-T, Jung G, Zöllner AM, Tiburcy M, Riegler J, Matsa E, Shukla P, Zhuge Y, Chour T, Chen VC, Burridge PW, Karakikes I, Kuhl E, Bernstein D, Couture LA, Gold JD, Zimmermann WH, Wu JC (2018) Passive stretch induces structural and functional maturation of engineered heart muscle as predicted by computational modeling. Stem Cells 36 : 265-277. https://doi.org/10.1002/stem.2732

4. Acimovic I, Refaat MM, Moreau A, Salykin A, Reiken S, Sleiman Y, Souidi M, Přibyl J, Kajava AV, Richard S, Lu JT, Chevalier P, Skládal P, Dvořak P, Rotrekl V, Marks AR, Scheinman MM, Lacampagne A, Meli AC (2018) Post-translational modifications and diastolic calcium leak associated to the novel RyR2-D3638A mutation lead to CPVT in patient-specific hiPSC-derived cardiomyocytes. J Clin Med 7. https://doi.org/10.3390/ jcm7110423

5. Agarwal A, Goss JA, Cho A, McCain ML, Parker KK (2013) Microfluidic heart on a chip for higher throughput 
pharmacological studies. Lab Chip 13:3599-3608. https://doi.org/ $10.1039 / \mathrm{c} 31 \mathrm{c} 50350 \mathrm{j}$

6. Alford PW, Feinberg AW, Sheehy SP, Parker KK (2010) Biohybrid thin films for measuring contractility in engineered cardiovascular muscle. Biomaterials 31:3613-3621. https://doi. org/10.1016/j.biomaterials.2010.01.079

7. Amano Y, Nishiguchi A, Matsusaki M, Iseoka H, Miyagawa S, Sawa Y, Seo M, Yamaguchi T, Akashi M (2016) Development of vascularized iPSC derived 3D-cardiomyocyte tissues by filtration layer-by-layer technique and their application for pharmaceutical assays. Acta Biomater 33:110-121. https://doi.org/10.1016/j. actbio.2016.01.033

8. Andrea L, Andrea L, Andrea L, Alessandro B, Alessandro B, Alessandro B, D PJ, D PJ, D PJ, M BK, M BK, M BK, Shiv B, Michael R, Michael R, Michael R, E MC, E MC, E MC, E MC, E MC, E MC, J SN, J SN, J SN, J SN (2018) Afterload promotes maturation of human induced pluripotent stem cell derived cardiomyocytes in engineered heart tissues. J Mol Cell Cardiol 118:147-158

9. Antoniou C-K, Dilaveris P, Manolakou P, Galanakos S, Magkas N, Gatzoulis K, Tousoulis D (2017) QT prolongation and malignant arrhythmia: how serious a problem? Eur Cardiol 12:112-120. https://doi.org/10.15420/ecr.2017:16:1

10. Ban K, Bae S, Yoon Y-S (2017) Current strategies and challenges for purification of cardiomyocytes derived from human pluripotent stem cells. Theranostics 7:2067-2077. https://doi.org/10. 7150/thno.19427

11. Bang S, Jeong S, Choi N, Kim HN (2019) Brain-on-a-chip: a history of development and future perspective. Biomicrofluidics 13. https://doi.org/10.1063/1.5120555

12. Barr JT, Tran TB, Rock BM, Wahlstrom JL, Dahal UP (2020) Strain-dependent variability of early discovery small molecule pharmacokinetics in mice: does strain matter? Drug Metab Dispos 48:613-621. https://doi.org/10.1124/dmd.120.090621

13. Beauchamp P, Jackson CB, Ozhathil LC, Agarkova I, Galindo CL, Sawyer DB, Suter TM, Zuppinger C (2020) 3D Co-culture of hiPSC-derived cardiomyocytes with cardiac fibroblasts improves tissue-like features of cardiac spheroids. Front Mol Biosci 7. https://doi.org/10.3389/fmolb.2020.00014

14. Bergmann O, Zdunek S, Felker A, Salehpour M, Alkass K, Bernard S, Sjostrom SL, Szewczykowska M, Jackowska T, Dos Remedios C, Malm T, Andrä M, Jashari R, Nyengaard JR, Possnert G, Jovinge S, Druid H, Frisén J (2015) Dynamics of cell generation and turnover in the human heart. Cell 161:1566-1575. https://doi.org/10.1016/j.cell.2015.05.026

15. Bergström G, Christoffersson J, Schwanke K, Zweigerdt R, Mandenius C-F (2015) Stem cell derived in vivo-like human cardiac bodies in a microfluidic device for toxicity testing by beating frequency imaging. Lab Chip 15:3242-3249. https://doi.org/10. 1039/c5lc00449g

16. Beussman KM, Rodriguez ML, Leonard A, Taparia N, Thompson CR, Sniadecki NJ (2016) Micropost arrays for measuring stem cell-derived cardiomyocyte contractility. Methods 94:43-50. https://doi.org/10.1016/j.ymeth.2015.09.005

17. Bhaskaran M, Cornwell PD, Sorden SD, Elwell MR, Russell NR, Pritt ML, Vahle JL (2018) Pancreatic effects of a Bruton's tyrosine kinase small-molecule inhibitor in rats are strain-dependent. Toxicol Pathol 46:460-472. https://doi.org/10.1177/ 0192623318770163

18. Bhatia SN, Ingber DE (2014) Microfluidic organs-on-chips. Nature Biotechnology 32:760-772. https://doi.org/10.1038/nbt. 2989

19. Biendarra-Tiegs SM, Li X, Ye D, Brandt EB, Ackerman MJ, Nelson TJ (2019) Single-cell RNA-sequencing and optical electrophysiology of human induced pluripotent stem cell-derived cardiomyocytes reveal discordance between cardiac subtype- associated gene expression patterns and electrophysiological phenotypes. Stem Cells Dev 28:659-673. https://doi.org/10.1089/scd. 2019.0030

20. Blinova K, Dang Q, Millard D, Smith G, Pierson J, Guo L, Brock M, Lu HR, Kraushaar U, Zeng H, Shi H, Zhang X, Sawada K, Osada T, Kanda Y, Sekino Y, Pang L, Feaster TK, Kettenhofen R, Stockbridge N, Strauss DG, Gintant G (2018) International multisite study of human-induced pluripotent stem cell-derived cardiomyocytes for drug proarrhythmic potential assessment. Cell Rep 24:3582-3592. https://doi.org/10.1016/j.celrep.2018. 08.079

21. Branco MA, Cotovio JP, Rodrigues CAV, Vaz SH, Fernandes TG, Moreira LM, Cabral JMS, Diogo MM (2019) Transcriptomic analysis of 3D cardiac differentiation of human induced pluripotent stem cells reveals faster cardiomyocyte maturation compared to 2D culture. Scientific Reports 9:9229. https:// doi.org/10.1038/s41598-019-45047-9

22. Breckwoldt K, Letuffe-Brenière D, Mannhardt I, Schulze T, Ulmer B, Werner T, Benzin A, Klampe B, Reinsch MC, Laufer S, Shibamiya A, Prondzynski M, Mearini G, Schade D, Fuchs S, Neuber C, Krämer E, Saleem U, Schulze ML, Rodriguez ML, Eschenhagen T, Hansen A (2017) Differentiation of cardiomyocytes and generation of human engineered heart tissue. Nature Protocols 12:1177-1197. https://doi.org/10.1038/nprot. 2017.033

23. Burridge PW, Li YF, Matsa E, Wu H, Ong S-G, Sharma A, Holmström A, Chang AC, Coronado MJ, Ebert AD, Knowles JW, Telli ML, Witteles RM, Blau HM, Bernstein D, Altman RB, Wu JC (2016) Human induced pluripotent stem cell-derived cardiomyocytes recapitulate the predilection of breast cancer patients to doxorubicin-induced cardiotoxicity. Nat Med 22:547556. https://doi.org/10.1038/nm.4087

24. Burridge PW, Matsa E, Shukla P, Lin ZC, Churko JM, Ebert AD, Lan F, Diecke S, Huber B, Mordwinkin NM, Plews JR, Abilez OJ, Cui B, Gold JD, Wu JC (2014) Chemically defined generation of human cardiomyocytes. Nature Methods 11:855-860. https://doi. org/10.1038/nmeth.2999

25. Burridge PW, Thompson S, Millrod MA, Weinberg S, Yuan X, Peters A, Mahairaki V, Koliatsos VE, Tung L, Zambidis ET (2011) A universal system for highly efficient cardiac differentiation of human induced pluripotent stem cells that eliminates interline variability. PLOS ONE 6:e18293. https://doi.org/10.1371/ journal.pone. 0018293

26. Burton R-AB, Tomek J, Ambrosi CM, Larsen HE, Sharkey AR, Capel RA, Corbett AD, Bilton S, Klimas A, Stephens G, Cremer M, Bose SJ, Li D, Gallone G, Herring N, Mann EO, Kumar A, Kramer H, Entcheva E, Paterson DJ, Bub G (2020) Optical interrogation of sympathetic neuronal effects on macroscopic cardiomyocyte network dynamics. iScience 23:101334. https://doi.org/ 10.1016/j.isci.2020.101334

27. Ca B, Ds van N, I L (2015) Antidepressant-like effects of buprenorphine in rats are strain dependent. In: Behavioural brain research. https://pubmed.ncbi.nlm.nih.gov/25453747/. Accessed 25 Jan 2021

28. Carson D, Hnilova M, Yang X, Nemeth CL, Tsui JH, Smith AST, Jiao A, Regnier M, Murry CE, Tamerler C, Kim D-H (2016) Nanotopography-induced structural anisotropy and sarcomere development in human cardiomyocytes derived from induced pluripotent stem cells. ACS Appl Mater Interfaces 8:21923-21932. https://doi.org/10.1021/acsami.5b11671

29. Caspi O, Huber I, Gepstein A, Arbel G, Maizels L, Boulos M, Gepstein L (2013) Modeling of arrhythmogenic right ventricular cardiomyopathy with human induced pluripotent stem cells. Circ Cardiovasc Genet 6:557-568. https://doi.org/10.1161/ CIRCGENETICS.113.000188 
30. Chang S-Y, Weber EJ, Sidorenko VS, Chapron A, Yeung CK, Gao C, Mao Q, Shen D, Wang J, Rosenquist TA, Dickman KG, Neumann T, Grollman AP, Kelly EJ, Himmelfarb J, Eaton DL (2017) Human liver-kidney model elucidates the mechanisms of aristolochic acid nephrotoxicity. JCI Insight 2. https://doi.org/10. 1172/jci.insight.95978

31. Chaudhari U, Nemade H, Wagh V, Gaspar JA, Ellis JK, Srinivasan SP, Spitkovski D, Nguemo F, Louisse J, Bremer S, Hescheler J, Keun HC, Hengstler JG, Sachinidis A (2016) Identification of genomic biomarkers for anthracycline-induced cardiotoxicity in human iPSC-derived cardiomyocytes: an in vitro repeated exposure toxicity approach for safety assessment. Arch Toxicol 90:2763-2777. https://doi.org/10.1007/s00204015-1623-5

32. Choucha-Snouber L, Aninat C, Grsicom L, Madalinski G, Brochot C, Poleni PE, Razan F, Guillouzo CG, Legallais C, Corlu A, Leclerc E (2013) Investigation of ifosfamide nephrotoxicity induced in a liver-kidney co-culture biochip. Biotechnol Bioeng 110:597-608. https://doi.org/10.1002/bit.24707

33. Chramiec A, Teles D, Yeager K, Marturano-Kruik A, Pak J, Chen T, Hao L, Wang M, Lock R, Tavakol DN, Lee MB, Kim J, Ronaldson-Bouchard K, Vunjak-Novakovic G (2020) Integrated human organ-on-a-chip model for predictive studies of anti-tumor drug efficacy and cardiac safety. Lab Chip 20:4357-4372. https:// doi.org/10.1039/D0LC00424C

34. Christoffersson J, Meier F, Kempf H, Schwanke K, Coffee M, Beilmann M, Zweigerdt R, Mandenius C-F (2018) A cardiac cell outgrowth assay for evaluating drug compounds using a cardiac spheroid-on-a-chip device. Bioengineering (Basel) 5. https://doi. org/10.3390/bioengineering5020036

35. Colatsky T, Fermini B, Gintant G, Pierson JB, Sager P, Sekino Y, Strauss DG, Stockbridge N (2016) The Comprehensive in Vitro Proarrhythmia Assay (CiPA) initiative - update on progress. J Pharmacol Toxicol Methods 81:15-20. https://doi.org/10.1016/j. vascn.2016.06.002

36. Correia C, Koshkin A, Duarte P, Hu D, Carido M, Sebastião MJ, Gomes-Alves P, Elliott DA, Domian IJ, Teixeira AP, Alves PM, Serra M (2018) 3D aggregate culture improves metabolic maturation of human pluripotent stem cell derived cardiomyocytes. Biotechnol Bioeng 115:630-644. https://doi.org/10.1002/bit. 26504

37. Coughtrie AL, Behr ER, Layton D, Marshall V, Camm AJ, Shakir SAW (2017) Drugs and life-threatening ventricular arrhythmia risk: results from the DARE study cohort. BMJ Open 7: e016627. https://doi.org/10.1136/bmjopen-2017-016627

38. Cubeddu LX (2016) Drug-induced Inhibition and Trafficking Disruption of ion Channels: Pathogenesis of QT Abnormalities and Drug-induced Fatal Arrhythmias. Curr Cardiol Rev 12:141154. https://doi.org/10.2174/1573403x12666160301120217

39. Cui Z, Ni NC, Wu J, Du G-Q, He S, Yau TM, Weisel RD, Sung H-W, Li R-K (2018) Polypyrrole-chitosan conductive biomaterial synchronizes cardiomyocyte contraction and improves myocardial electrical impulse propagation. Theranostics 8:2752-2764. https://doi.org/10.7150/thno.22599

40. Cyganek L, Tiburcy M, Sekeres K, Gerstenberg K, Bohnenberger H, Lenz C, Henze S, Stauske M, Salinas G, Zimmermann W-H, Hasenfuss G, Guan K (2018) Deep phenotyping of human induced pluripotent stem cell-derived atrial and ventricular cardiomyocytes. JCI Insight 3. https://doi.org/10.1172/jci.insight. 99941

41. Daily NJ, Yin Y, Kemanli P, Ip B, Wakatsuki T (2015) Improving cardiac action potential measurements: 2D and 3D cell culture. J Bioeng Biomed Sci 5. https://doi.org/10.4172/2155-9538. 1000168

42. Deng J, Wei W, Chen Z, Lin B, Zhao W, Luo Y, Zhang X (2019) Engineered liver-on-a-chip platform to mimic liver functions and its biomedical applications: a review. Micromachines 10:676. https://doi.org/10.3390/mi10100676

43. Denning C, Borgdorff V, Crutchley J, Firth KSA, George V, Kalra S, Kondrashov A, Hoang MD, Mosqueira D, Patel A, Prodanov L, Rajamohan D, Skarnes WC, Smith JGW, Young LE (2016) Cardiomyocytes from human pluripotent stem cells: From laboratory curiosity to industrial biomedical platform. Biochimica et Biophysica Acta (BBA) - Molecular Cell Research 1863:17281748. https://doi.org/10.1016/j.bbamcr.2015.10.014

44. DesRochers TM, Suter L, Roth A, Kaplan DL (2013) Bioengineered 3D human kidney tissue, a platform for the determination of nephrotoxicity. PLoS One 8:e59219. https://doi.org/ 10.1371/journal.pone.0059219

45. Devalla HD, Passier R (2018) Cardiac differentiation of pluripotent stem cells and implications for modeling the heart in health and disease. Sci Transl Med 10. https://doi.org/10.1126/ scitranslmed.aah5457

46. Devalla HD, Schwach V, Ford JW, Milnes JT, El-Haou S, Jackson C, Gkatzis K, Elliott DA, Chuva de Sousa Lopes SM, Mummery CL, Verkerk AO, Passier R (2015) Atrial-like cardiomyocytes from human pluripotent stem cells are a robust preclinical model for assessing atrial-selective pharmacology. EMBO Mol Med 7:394-410. https://doi.org/10.15252/emmm. 201404757

47. Di Pasquale E, Lodola F, Miragoli M, Denegri M, Avelino-Cruz JE, Buonocore M, Nakahama H, Portararo P, Bloise R, Napolitano C, Condorelli G, Priori SG (2013) CaMKII inhibition rectifies arrhythmic phenotype in a patient-specific model of catecholaminergic polymorphic ventricular tachycardia. Cell Death Dis 4:e843. https://doi.org/10.1038/cddis.2013.369

48. Dick E, Kalra S, Anderson D, George V, Ritso M, Laval SH, Barresi R, Aartsma-Rus A, Lochmüller H, Denning C (2013) Exon skipping and gene transfer restore dystrophin expression in human induced pluripotent stem cells-cardiomyocytes harboring DMD mutations. Stem Cells Dev 22:2714-2724. https://doi.org/ 10.1089/scd.2013.0135

49. Dillenburg RF, Nathan P, Mertens L (2013) Educational paper: decreasing the burden of cardiovascular disease in childhood cancer survivors: an update for the pediatrician. Eur J Pediatr 172: 1149-1160. https://doi.org/10.1007/s00431-013-1931-9

50. Eder A, Vollert I, Hansen A, Eschenhagen T (2016) Human engineered heart tissue as a model system for drug testing. Adv Drug Deliv Rev 96:214-224. https://doi.org/10.1016/j.addr.2015.05. 010

51. El-Battrawy I, Zhao Z, Lan H, Cyganek L, Tombers C, Li X, Buljubasic F, Lang S, Tiburcy M, Zimmermann W-H, Utikal J, Wieland T, Borggrefe M, Zhou X-B, Akin I (2018) Electrical dysfunctions in human-induced pluripotent stem cell-derived cardiomyocytes from a patient with an arrhythmogenic right ventricular cardiomyopathy. Europace 20:f46-f56. https://doi.org/10. 1093/europace/euy042

52. Ellis BW, Acun A, Can UI, Zorlutuna P (2017) Human iPSCderived myocardium-on-chip with capillary-like flow for personalized medicine. Biomicrofluidics 11:024105. https://doi.org/10. 1063/1.4978468

53. Eng G, Lee BW, Protas L, Gagliardi M, Brown K, Kass RS, Keller G, Robinson RB, Vunjak-Novakovic G (2016) Autonomous beating rate adaptation in human stem cell-derived cardiomyocytes. Nature Communications 7:10312. https://doi.org/10.1038/ ncomms 10312

54. Feyen DAM, McKeithan WL, Bruyneel AAN, Spiering S, Hörmann L, Ulmer B, Zhang H, Briganti F, Schweizer M, Hegyi B, Liao Z, Pölönen R-P, Ginsburg KS, Lam CK, Serrano R, Wahlquist C, Kreymerman A, Vu M, Amatya PL, Behrens CS, Ranjbarvaziri S, Maas RGC, Greenhaw M, Bernstein D, Wu JC, Bers DM, Eschenhagen T, Metallo CM, Mercola M (2020) 
Metabolic maturation media improve physiological function of human iPSC-derived cardiomyocytes. Cell Reports 32:107925. https://doi.org/10.1016/j.celrep.2020.107925

55. Fong AH, Romero-López M, Heylman CM, Keating M, Tran D, Sobrino A, Tran AQ, Pham HH, Fimbres C, Gershon PD, Botvinick EL, George SC, Hughes CCW (2016) Threedimensional adult cardiac extracellular matrix promotes maturation of human induced pluripotent stem cell-derived cardiomyocytes. Tissue Eng Part A 22:1016-1025. https://doi. org/10.1089/ten.TEA.2016.0027

56. Giacomelli E, Bellin M, Sala L, van Meer BJ, Tertoolen LGJ, Orlova VV, Mummery CL (2017) Three-dimensional cardiac microtissues composed of cardiomyocytes and endothelial cells co-differentiated from human pluripotent stem cells. Development 144:1008-1017. https://doi.org/10.1242/dev.143438

57. Giacomelli E, Meraviglia V, Campostrini G, Cochrane A, Cao X, van Helden RWJ, Krotenberg Garcia A, Mircea M, Kostidis S, Davis RP, van Meer BJ, Jost CR, Koster AJ, Mei H, Míguez DG, Mulder AA, Ledesma-Terrón M, Pompilio G, Sala L, Salvatori DCF, Slieker RC, Sommariva E, de Vries AAF, Giera M, Semrau S, Tertoolen LGJ, Orlova VV, Bellin M, Mummery CL (2020) Human-iPSC-derived cardiac stromal cells enhance maturation in $3 \mathrm{D}$ cardiac microtissues and reveal non-cardiomyocyte contributions to heart disease. Cell Stem Cell 26:862-879.e11. https://doi. org/10.1016/j.stem.2020.05.004

58. Gladstone DJ, Black SE, Hakim AM (2002) Toward wisdom from failure. Stroke 33:2123-2136. https://doi.org/10.1161/01.STR. 0000025518.34157 .51

59. Goldfracht I, Efraim Y, Shinnawi R, Kovalev E, Huber I, Gepstein A, Arbel G, Shaheen N, Tiburcy M, Zimmermann WH, Machluf M, Gepstein L (2019) Engineered heart tissue models from hiPSC-derived cardiomyocytes and cardiac ECM for disease modeling and drug testing applications. Acta Biomater 92:145159. https://doi.org/10.1016/j.actbio.2019.05.016

60. Goversen B, van der Heyden MAG, van Veen TAB, de Boer TP (2018) The immature electrophysiological phenotype of iPSCCMs still hampers in vitro drug screening: special focus on IK1. Pharmacology \& Therapeutics 183:127-136. https://doi.org/10. 1016/j.pharmthera.2017.10.001

61. Grosberg A, Nesmith AP, Goss JA, Brigham MD, McCain ML, Parker KK (2012) Muscle on a chip: in vitro contractility assays for smooth and striated muscle. J Pharmacol Toxicol Methods 65: 126-135. https://doi.org/10.1016/j.vascn.2012.04.001

62. Gunness P, Mueller D, Shevchenko V, Heinzle E, IngelmanSundberg M, Noor F (2013) 3D organotypic cultures of human HepaRG cells: a tool for in vitro toxicity studies. Toxicol Sci 133: 67-78. https://doi.org/10.1093/toxsci/kft021

63. Guo Y, Pu WT (2020) Cardiomyocyte maturation: new phase in development. Circ Res 126:1086-1106. https://doi.org/10.1161/ CIRCRESAHA.119.315862

64. H Z, L T, M S, C T, H W, M G, Dt P, Jc W (2019) Generation of quiescent cardiac fibroblasts from human induced pluripotent stem cells for in vitro modeling of cardiac fibrosis. In: Circulation research. https://pubmed.ncbi.nlm.nih.gov/ 31288631/. Accessed 26 Jan 2021

65. Halbach M, Egert U, Hescheler J, Banach K (2003) Estimation of action potential changes from field potential recordings in multicellular mouse cardiac myocyte cultures. Cell Physiol Biochem 13:271-284. https://doi.org/10.1159/000074542

66. Hattori F, Chen H, Yamashita H, Tohyama S, Satoh Y-S, Yuasa S, Li W, Yamakawa H, Tanaka T, Onitsuka T, Shimoji K, Ohno Y, Egashira T, Kaneda R, Murata M, Hidaka K, Morisaki T, Sasaki E, Suzuki T, Sano M, Makino S, Oikawa S, Fukuda K (2010) Nongenetic method for purifying stem cell-derived cardiomyocytes. Nat Methods 7:61-66. https://doi.org/10.1038/ nmeth.1403
67. Haverkamp W, Breithardt G, Camm AJ, Janse MJ, Rosen MR, Antzelevitch C, Escande D, Franz M, Malik M, Moss A, Shah R (2000) The potential for QT prolongation and proarrhythmia by non-antiarrhythmic drugs: clinical and regulatory implications. Report on a policy conference of the European Society of Cardiology. Eur Heart J 21:1216-1231. https://doi.org/10.1053/ euhj.2000.2249

68. Hernández D, Millard R, Sivakumaran P, Kong A, Mitchell G, Pebay A, Sheperd R, Dusting G, Lim S (2018) Influence of continuous electrical stimulation on development of human cardiomyocytes from induced pluripotent stem cells. Conditioning Medicine: 1

69. Herron TJ, Lee P, Jalife J (2012) Optical imaging of voltage and calcium in cardiac cells \& tissues. Circ Res 110:609-623. https:// doi.org/10.1161/CIRCRESAHA.111.247494

70. Higa A, Hoshi H, Yanagisawa Y, Ito E, Morisawa G, Imai J-I, Watanabe S, Takagi M (2017) Evaluation system for arrhythmogenic potential of drugs using human-induced pluripotent stem cell-derived cardiomyocytes and gene expression analysis. J Toxicol Sci 42:755-761. https://doi.org/10.2131/jts.42.755

71. Holmgren G, Sartipy P, Andersson CX, Lindahl A, Synnergren J (2018) Expression profiling of human pluripotent stem cellderived cardiomyocytes exposed to doxorubicin-integration and visualization of multi-omics data. Toxicol Sci 163:182-195. https://doi.org/10.1093/toxsci/kfy012

72. Horikoshi Y, Yan Y, Terashvili M, Wells C, Horikoshi H, Fujita S, Bosnjak ZJ, Bai X (2019) Fatty acid-treated induced pluripotent stem cell-derived human cardiomyocytes exhibit adult cardiomyocyte-like energy metabolism phenotypes. Cells 8 . https://doi.org/10.3390/cells8091095

73. Hortigon-Vinagre MP, Zamora V, Burton FL, Green J, Gintant GA, Smith GL (2016) The use of ratiometric fluorescence measurements of the voltage sensitive dye Di-4-ANEPPS to examine action potential characteristics and drug effects on human induced pluripotent stem cell-derived cardiomyocytes. Toxicol Sci 154: 320-331. https://doi.org/10.1093/toxsci/kfw171

74. Houser SR, Margulies KB, Murphy AM, Spinale FG, Francis GS, Prabhu SD, Rockman HA, Kass DA, Molkentin JD, Sussman MA, Koch WJ, Koch W, American Heart Association Council on Basic Cardiovascular Sciences, Council on Clinical Cardiology, and Council on Functional Genomics and Translational Biology (2012) Animal models of heart failure: a scientific statement from the American Heart Association. Circ Res 111:131-150. https://doi.org/ 10.1161/RES.0b013e3182582523

75. Itzhaki I, Maizels L, Huber I, Gepstein A, Arbel G, Caspi O, Miller L, Belhassen B, Nof E, Glikson M, Gepstein L (2012) Modeling of catecholaminergic polymorphic ventricular tachycardia with patient-specific human-induced pluripotent stem cells. J Am Coll Cardiol 60:990-1000. https://doi.org/10.1016/j.jacc. 2012.02.066

76. Itzhaki I, Maizels L, Huber I, Zwi-Dantsis L, Caspi O, Winterstern A, Feldman O, Gepstein A, Arbel G, Hammerman H, Boulos M, Gepstein L (2011) Modelling the long QT syndrome with induced pluripotent stem cells. Nature 471:225-229. https://doi.org/10. 1038/nature09747

77. Jang K-J, Mehr AP, Hamilton GA, McPartlin LA, Chung S, Suh K-Y, Ingber DE (2013) Human kidney proximal tubule-on-a-chip for drug transport and nephrotoxicity assessment. Integr Biol (Camb) 5:1119-1129. https://doi.org/10.1039/c3ib40049b

78. Jang K-J, Otieno MA, Ronxhi J, Lim H-K, Ewart L, Kodella KR, Petropolis DB, Kulkarni G, Rubins JE, Conegliano D, Nawroth J, Simic D, Lam W, Singer M, Barale E, Singh B, Sonee M, Streeter AJ, Manthey C, Jones B, Srivastava A, Andersson LC, Williams D, Park H, Barrile R, Sliz J, Herland A, Haney S, Karalis K, Ingber DE, Hamilton GA (2019) Reproducing human and cross-species 
drug toxicities using a Liver-Chip. Science Translational Medicine 11. https://doi.org/10.1126/scitranslmed.aax5516

79. Johannesen L, Vicente J, Mason JW, Sanabria C, Waite-Labott K, Hong M, Guo P, Lin J, Sørensen JS, Galeotti L, Florian J, Ugander M, Stockbridge N, Strauss DG (2014) Differentiating drug-induced multichannel block on the electrocardiogram: randomized study of dofetilide, quinidine, ranolazine, and verapamil. Clin Pharmacol Ther 96:549-558. https://doi.org/10.1038/clpt.2014.155

80. Jouni M, Si-Tayeb K, Es-Salah-Lamoureux Z, Latypova X, Champon B, Caillaud A, Rungoat A, Charpentier F, Loussouarn G, Baró I, Zibara K, Lemarchand P, Gaborit N (2015) Toward personalized medicine: using cardiomyocytes differentiated from urine-derived pluripotent stem cells to recapitulate electrophysiological characteristics of type 2 long QT syndrome. J Am Heart Assoc 4:e02159. https://doi.org/10.1161/JAHA.115.002159

81. Jung CB, Moretti A, Mederos y Schnitzler M, Iop L, Storch U, Bellin M, Dorn T, Ruppenthal S, Pfeiffer S, Goedel A, Dirschinger RJ, Seyfarth M, Lam JT, Sinnecker D, Gudermann T, Lipp P, Laugwitz K-L (2012) Dantrolene rescues arrhythmogenic RYR2 defect in a patient-specific stem cell model of catecholaminergic polymorphic ventricular tachycardia. EMBO Mol Med 4:180-191. https://doi.org/10.1002/emmm.201100194

82. Kamakura T, Makiyama T, Sasaki K, Yoshida Y, Wuriyanghai Y, Chen J, Hattori T, Ohno S, Kita T, Horie M, Yamanaka S, Kimura $\mathrm{T}$ (2013) Ultrastructural maturation of human-induced pluripotent stem cell-derived cardiomyocytes in a long-term culture. Circ J 77: 1307-1314. https://doi.org/10.1253/circj.cj-12-0987

83. Kamdar F, Das S, Gong W, Klaassen Kamdar A, Meyers TA, Shah P, Ervasti JM, Townsend D, Kamp TJ, Wu JC, Garry MG, Zhang J, Garry DJ (2020) Stem cell-derived cardiomyocytes and beta-adrenergic receptor blockade in Duchenne muscular dystrophy cardiomyopathy. J Am Coll Cardiol 75:1159-1174. https:// doi.org/10.1016/j.jacc.2019.12.066

84. Kanda Y, Yamazaki D, Osada T, Yoshinaga T, Sawada K (2018) Development of torsadogenic risk assessment using human induced pluripotent stem cell-derived cardiomyocytes: Japan iPS Cardiac Safety Assessment (JiCSA) update. J Pharmacol Sci 138:233-239. https://doi.org/10.1016/j.jphs.2018.10.010

85. Karbassi E, Fenix A, Marchiano S, Muraoka N, Nakamura K, Yang X, Murry CE (2020) Cardiomyocyte maturation: advances in knowledge and implications for regenerative medicine. Nat Rev Cardiol 17:341-359. https://doi.org/10.1038/s41569-019-0331-x

86. Kim C, Wong J, Wen J, Wang S, Wang C, Spiering S, Kan NG, Forcales S, Puri PL, Leone TC, Marine JE, Calkins H, Kelly DP, Judge DP, Chen H-SV (2013) Studying arrhythmogenic right ventricular dysplasia with patient-specific iPSCs. Nature 494:105110. https://doi.org/10.1038/nature11799

87. Kistamás K, Veress R, Horváth B, Bányász T, Nánási PP, Eisner DA (2020) Calcium handling defects and cardiac arrhythmia syndromes. Front Pharmacol 11. https://doi.org/10.3389/fphar.2020.00072

88. Knottnerus SJG, Mengarelli I, Wüst RCI, Baartscheer A, Bleeker JC, Coronel R, Ferdinandusse S, Guan K, IJlst L, Li W, Luo X, Portero VM, Ulbricht Y, Visser G, Wanders RJA, Wijburg FA, Verkerk AO, Houtkooper RH, Bezzina CR (2020) Electrophysiological abnormalities in VLCAD deficient hiPSCcardiomyocytes can be improved by lowering Accumulation of fatty acid oxidation intermediates. Int J Mol Sci 21. https://doi. org/10.3390/ijms21072589

89. Knowles DA, Burrows CK, Blischak JD, Patterson KM, Serie DJ, Norton N, Ober C, Pritchard JK, Gilad Y (2018) Determining the genetic basis of anthracycline-cardiotoxicity by molecular response QTL mapping in induced cardiomyocytes. Elife 7. https://doi.org/10.7554/eLife.33480

90. Kocadal K, Saygi S, Alkas FB, Sardas S (2018) Drug-associated cardiovascular risks: a retrospective evaluation of withdrawn drugs. North Clin Istanb 6:196-202. https://doi.org/10.14744/ nci.2018.44977

91. Kopljar I, Lu HR, Van Ammel K, Otava M, Tekle F, Teisman A, Gallacher DJ (2018) Development of a human iPSC cardiomyocyte-based scoring system for cardiac hazard identification in early drug safety de-risking. Stem Cell Reports 11:13651377. https://doi.org/10.1016/j.stemcr.2018.11.007

92. Kujala VJ, Pasqualini FS, Goss JA, Nawroth JC, Parker KK (2016) Laminar ventricular myocardium on a microelectrode array-based chip. J Mater Chem B 4:3534-3543. https://doi.org/ 10.1039/C6TB00324A

93. Kumar S, Marfatia R, Tannenbaum S, Yang C, Avelar E (2012) Doxorubicin-induced cardiomyopathy 17 years after chemotherapy. Tex Heart Inst J 39:424-427

94. Kuppusamy KT, Jones DC, Sperber H, Madan A, Fischer KA, Rodriguez ML, Pabon L, Zhu W-Z, Tulloch NL, Yang X, Sniadecki NJ, Laflamme MA, Ruzzo WL, Murry CE, RuoholaBaker H (2015) Let-7 family of microRNA is required for maturation and adult-like metabolism in stem cell-derived cardiomyocytes. Proc Natl Acad Sci USA 112:E2785-E2794. https://doi.org/10.1073/pnas.1424042112

95. LaBarge W, Mattappally S, Kannappan R, Fast VG, Pretorius D, Berry JL, Zhang J (2019) Maturation of three-dimensional, hiPSC-derived cardiomyocyte spheroids utilizing cyclic, uniaxial stretch and electrical stimulation. PLoS One 14:e0219442. https:// doi.org/10.1371/journal.pone.0219442

96. Lee J, Kim S (2018) Kidney-on-a-chip: a new technology for predicting drug efficacy, interactions, and drug-induced nephrotoxicity. Curr Drug Metab 19:577-583. https://doi.org/10.2174/ 1389200219666180309101844

97. Lemme M, Ulmer BM, Lemoine MD, Zech ATL, Flenner F, Ravens U, Reichenspurner H, Rol-Garcia M, Smith G, Hansen A, Christ T, Eschenhagen T (2018) Atrial-like engineered heart tissue: an in vitro model of the human atrium. Stem Cell Reports 11:1378-1390. https://doi.org/10.1016/j.stemcr.2018.10.008

98. Lenneman CG, Sawyer DB (2016) Cardio-oncology: an update on cardiotoxicity of cancer-related treatment. Circ Res 118:1008 1020. https://doi.org/10.1161/CIRCRESAHA.115.303633

99. Lester RM, Olbertz J (2016) Early drug development: assessment of proarrhythmic risk and cardiovascular safety. Expert Review of Clinical Pharmacology 9:1611-1618. https://doi.org/10.1080/ 17512433.2016.1245142

100. Li J, Minami I, Yu L, Tsuji K, Nakajima M, Qiao J, Suzuki M, Shimono K, Nakatsuji N, Kotera H, Liu L, Chen Y (2016) Extracellular recordings of patterned human pluripotent stem cell-derived cardiomyocytes on aligned fibers. In: Stem Cells International. https://www.hindawi.com/journals/sci/2016/ 2634013/. Accessed 26 Jan 2021

101. Li J, Zhang L, Yu L, Minami I, Miyagawa S, Hörning M, Dong J, Qiao J, Qu X, Hua Y, Fujimoto N, Shiba Y, Zhao Y, Tang F, Chen Y, Sawa Y, Tang C, Liu L (2020) Circulating re-entrant waves promote maturation of hiPSC-derived cardiomyocytes in selforganized tissue ring. Commun Biol 3:1-12. https://doi.org/10. 1038/s42003-020-0853-0

102. Li Q, Li R, Wall SB, Dunigan K, Ren C, Jilling T, Rogers LK, Tipple TE (2018) Aurothioglucose does not improve alveolarization or elicit sustained Nrf2 activation in C57BL/6 models of bronchopulmonary dysplasia. Am J Physiol Lung Cell Mol Physiol 314:L736-L742. https://doi.org/10.1152/ajplung.00539.2017

103. Li Q, Wang J, Wu Q, Cao N, Yang H-T (2020) Perspective on human pluripotent stem cell-derived cardiomyocytes in heart disease modeling and repair. STEM CELLS Translational Medicine 9:1121-1128. https://doi.org/10.1002/sctm.19-0340

104. Li Z, Jiang L, Zhu Y, Su W, Xu C, Tao T, Shi Y, Qin J (2018) Assessment of hepatic metabolism-dependent nephrotoxicity on 
an organs-on-a-chip microdevice. Toxicol In Vitro 46:1-8. https:// doi.org/10.1016/j.tiv.2017.10.005

105. Lian X, Zhang J, Azarin SM, Zhu K, Hazeltine LB, Bao X, Hsiao C, Kamp TJ, Palecek SP (2013) Directed cardiomyocyte differentiation from human pluripotent stem cells by modulating $\mathrm{Wnt} / \beta$ catenin signaling under fully defined conditions. Nature Protocols 8:162-175. https://doi.org/10.1038/nprot.2012.150

106. Liang P, Lan F, Lee AS, Gong T, Sanchez-Freire V, Wang Y, Diecke S, Sallam K, Knowles JW, Wang PJ, Nguyen PK, Bers DM, Robbins RC, Wu JC (2013) Drug screening using a library of human induced pluripotent stem cell-derived cardiomyocytes reveals disease-specific patterns of cardiotoxicity. Circulation 127:1677-1691. https://doi.org/ 10.1161/CIRCULATIONAHA.113.001883

107. Lind JU, Yadid M, Perkins I, O'Connor BB, Eweje F, Chantre CO, Hemphill MA, Yuan H, Campbell PH, Vlassak JJ, Parker KK (2017) Cardiac microphysiological devices with flexible thin-film sensors for higher-throughput drug screening. Lab Chip 17:36923703. https://doi.org/10.1039/C7LC00740J

108. Liu H, Bolonduro OA, Hu N, Ju J, Rao AA, Duffy BM, Huang Z, Black LD, Timko BP (2020) Heart-on-a-chip model with integrated extra- and intracellular bioelectronics for monitoring cardiac electrophysiology under acute hypoxia. Nano Lett 20:25852593. https://doi.org/10.1021/acs.nanolett.0c00076

109. Liu J, Sun N, Bruce MA, Wu JC, Butte MJ (2012) Atomic force mechanobiology of pluripotent stem cell-derived cardiomyocytes. PLoS One 7:e37559. https://doi.org/10.1371/journal.pone. 0037559

110. Liu Y, Bai H, Guo F, Thai PN, Luo X, Zhang P, Yang C, Feng X, Zhu D, Guo J, Liang P, Xu Z, Yang H, Lu X (2020) PGC-1 $\alpha$ activator ZLN005 promotes maturation of cardiomyocytes derived from human embryonic stem cells. Aging (Albany NY) 12:7411-7430. https://doi.org/10.18632/aging.103088

111. Łoboda A, Dulak J (2020) Muscle and cardiac therapeutic strategies for Duchenne muscular dystrophy: past, present, and future. Pharmacol Rep 72:1227-1263. https://doi.org/10.1007/s43440020-00134-x

112. Magdy T, Burmeister BT, Burridge PW (2016) Validating the pharmacogenomics of chemotherapy-induced cardiotoxicity: what is missing? Pharmacol Ther 168:113-125. https://doi.org/ 10.1016/j.pharmthera.2016.09.009

113. Maizels L, Huber I, Arbel G, Tijsen AJ, Gepstein A, Khoury A, Gepstein L (2017) Patient-specific drug screening using a human induced pluripotent stem cell model of catecholaminergic polymorphic ventricular tachycardia type 2. Circ Arrhythm Electrophysiol 10. https://doi.org/10.1161/CIRCEP.116.004725

114. Mannhardt I, Breckwoldt K, Letuffe-Brenière D, Schaaf S, Schulz H, Neuber C, Benzin A, Werner T, Eder A, Schulze T, Klampe B, Christ T, Hirt MN, Huebner N, Moretti A, Eschenhagen T, Hansen A (2016) Human engineered heart tissue: analysis of contractile force. Stem Cell Reports 7:29-42. https://doi.org/10.1016/ j.stemcr.2016.04.011

115. Maoz BM, Herland A, Henry OYF, Leineweber WD, Yadid M, Doyle J, Mannix R, Kujala VJ, FitzGerald EA, Parker KK, Ingber DE (2017) Organs-on-chips with combined multi-electrode array and transepithelial electrical resistance measurement capabilities. Lab Chip 17:2294-2302. https://doi.org/10.1039/C7LC00412E

116. Marsano A, Conficconi C, Lemme M, Occhetta P, Gaudiello E, Votta E, Cerino G, Redaelli A, Rasponi M (2016) Beating heart on a chip: a novel microfluidic platform to generate functional 3D cardiac microtissues. Lab Chip 16:599-610. https://doi.org/10. 1039/C5LC01356A

117. Martewicz S, Michielin F, Serena E, Zambon A, Mongillo M, Elvassore N (2012) Reversible alteration of calcium dynamics in cardiomyocytes during acute hypoxia transient in a microfluidic platform. Integr Biol (Camb) 4:153-164. https://doi.org/10.1039/ clib00087j
118. Mathur A, Loskill P, Shao K, Huebsch N, Hong S, Marcus SG, Marks N, Mandegar M, Conklin BR, Lee LP, Healy KE (2015) Human iPSC-based Cardiac Microphysiological System For Drug Screening Applications. Scientific Reports 5:8883. https://doi.org/ 10.1038/srep08883

119. McNair WP, Ku L, Taylor MRG, Fain PR, Dao D, Wolfel E, Mestroni L, Familial Cardiomyopathy Registry Research Group (2004) SCN5A mutation associated with dilated cardiomyopathy, conduction disorder, and arrhythmia. Circulation 110:2163-2167. https://doi.org/10.1161/01.CIR.0000144458.58660.BB

120. McNair WP, Sinagra G, Taylor MRG, Di Lenarda A, Ferguson DA, Salcedo EE, Slavov D, Zhu X, Caldwell JH, Mestroni L (2011) SCN5A mutations associate with arrhythmic dilated cardiomyopathy and commonly localize to the voltage-sensing mechanism. Journal of the American College of Cardiology 57:2160 2168. https://doi.org/10.1016/j.jacc.2010.09.084

121. van Meer BJ, Krotenberg A, Sala L, Davis RP, Eschenhagen T, Denning C, Tertoolen LGJ, Mummery CL (2019) Simultaneous measurement of excitation-contraction coupling parameters identifies mechanisms underlying contractile responses of hiPSCderived cardiomyocytes. Nature Communications 10:4325. https://doi.org/10.1038/s41467-019-12354-8

122. Mei J-C, Wu AYK, Wu P-C, Cheng N-C, Tsai W-B, Yu J (2014) Three-dimensional extracellular matrix scaffolds by microfluidic fabrication for long-term spontaneously contracted cardiomyocyte culture. Tissue Eng Part A 20:2931-2941. https://doi.org/10.1089/ ten.TEA.2013.0549

123. van Midwoud PM, Janse A, Merema MT, Groothuis GMM, Verpoorte E (2012) Comparison of biocompatibility and adsorption properties of different plastics for advanced microfluidic cell and tissue culture models. Anal Chem 84:3938-3944. https://doi. org/10.1021/ac300771z

124. Millard D, Dang Q, Shi H, Zhang X, Strock C, Kraushaar U, Zeng H, Levesque P, Lu H-R, Guillon J-M, Wu JC, Li Y, Luerman G, Anson B, Guo L, Clements M, Abassi YA, Ross J, Pierson J, Gintant G (2018) Cross-site reliability of human induced pluripotent stem cell-derived cardiomyocyte based safety assays using microelectrode arrays: results from a blinded CiPA pilot study. Toxicol Sci 164:550-562. https://doi.org/10.1093/toxsci/kfy110

125. Moradi E, Jalili-Firoozinezhad S, Solati-Hashjin M (2020) Microfluidic organ-on-a-chip models of human liver tissue. Acta Biomater 116:67-83. https://doi.org/10.1016/j.actbio.2020.08.041

126. Moretti A, Bellin M, Welling A, Jung CB, Lam JT, Bott-Flügel L, Dorn T, Goedel A, Höhnke C, Hofmann F, Seyfarth M, Sinnecker D, Schömig A, Laugwitz K-L (2010) Patient-specific induced pluripotent stem-cell models for long-QT syndrome. New England Journal of Medicine 363:1397-1409. https://doi.org/10. 1056/NEJMoa0908679

127. Morimoto Y, Mori S, Sakai F, Takeuchi S (2016) Human induced pluripotent stem cell-derived fiber-shaped cardiac tissue on a chip. Lab Chip 16:2295-2301. https://doi.org/10.1039/C6LC00422A

128. Mousavi Shaegh SA, De Ferrari F, Zhang YS, Nabavinia M, Binth Mohammad N, Ryan J, Pourmand A, Laukaitis E, Banan Sadeghian R, Nadhman A, Shin SR, Nezhad AS, Khademhosseini A, Dokmeci MR (2016) A microfluidic optical platform for real-time monitoring of $\mathrm{pH}$ and oxygen in microfluidic bioreactors and organ-on-chip devices. Biomicrofluidics 10:044111. https://doi.org/10.1063/1.4955155

129. Mummery CL, Zhang J, Ng ES, Elliott DA, Elefanty AG, Kamp TJ (2012) Differentiation of human embryonic stem cells and induced pluripotent stem cells to cardiomyocytes: a methods overview. Circ Res 111:344-358. https://doi.org/10.1161/ CIRCRESAHA.110.227512

130. Navaei A, Truong D, Heffernan J, Cutts J, Brafman D, Sirianni RW, Vernon B, Nikkhah M (2016) PNIPAAm-based biohybrid 
injectable hydrogel for cardiac tissue engineering. Acta Biomater 32:10-23. https://doi.org/10.1016/j.actbio.2015.12.019

131. Navarrete EG, Liang P, Lan F, Sanchez-Freire V, Simmons C, Gong T, Sharma A, Burridge PW, Patlolla B, Lee AS, Wu H, Beygui RE, Wu SM, Robbins RC, Bers DM, Wu JC (2013) Screening drug-induced arrhythmia [corrected] using human induced pluripotent stem cell-derived cardiomyocytes and lowimpedance microelectrode arrays. Circulation 128:S3-S13. https://doi.org/10.1161/CIRCULATIONAHA.112.000570

132. Nitsch S, Braun F, Ritter S, Scholz M, Schroeder IS (2018) Functional video-based analysis of $3 \mathrm{D}$ cardiac structures generated from human embryonic stem cells. Stem Cell Res 29:115-124. https://doi.org/10.1016/j.scr.2018.03.013

133. Nunes SS, Miklas JW, Liu J, Aschar-Sobbi R, Xiao Y, Zhang B, Jiang J, Massé S, Gagliardi M, Hsieh A, Thavandiran N, Laflamme MA, Nanthakumar K, Gross GJ, Backx PH, Keller G, Radisic M (2013) Biowire: a platform for maturation of human pluripotent stem cell-derived cardiomyocytes. Nature Methods 10:781-787. https://doi.org/10.1038/nmeth.2524

134. Oleaga C, Bernabini C, Smith AST, Srinivasan B, Jackson M, McLamb W, Platt V, Bridges R, Cai Y, Santhanam N, Berry B, Najjar S, Akanda N, Guo X, Martin C, Ekman G, Esch MB, Langer J, Ouedraogo G, Cotovio J, Breton L, Shuler ML, Hickman JJ (2016) Multi-Organ toxicity demonstration in a functional human in vitro system composed of four organs. Sci Rep 6. https://doi.org/10.1038/srep20030

135. Ong CS, Fukunishi T, Zhang H, Huang CY, Nashed A, Blazeski A, DiSilvestre D, Vricella L, Conte J, Tung L, Tomaselli GF, Hibino N (2017) Biomaterial-free three-dimensional bioprinting of cardiac tissue using human induced pluripotent stem cell derived cardiomyocytes. Scientific Reports 7:4566. https://doi.org/ 10.1038/s41598-017-05018-4

136. Palano G, Jansson M, Backmark A, Martinsson S, Sabirsh A, Hultenby K, Åkerblad P, Granberg KL, Jennbacken K, Müllers E, Hansson EM (2020) A high-content, in vitro cardiac fibrosis assay for high-throughput, phenotypic identification of compounds with anti-fibrotic activity. J Mol Cell Cardiol 142:105117. https://doi.org/10.1016/j.yjmcc.2020.04.002

137. Parikh J, Gurev V, Rice JJ (2017) Novel Two-Step Classifier for Torsades de Pointes Risk Stratification from Direct Features. Front Pharmacol 8:816. https://doi.org/10.3389/fphar.2017.00816

138. Park E, Gintant GA, Bi D, Kozeli D, Pettit SD, Pierson JB, Skinner M, Willard J, Wisialowski T, Koerner J, Valentin J-P (2018) Can non-clinical repolarization assays predict the results of clinical thorough QT studies? Results from a research consortium. Br J Pharmacol 175:606-617. https://doi.org/10.1111/bph. 14101

139. Park T-E, Mustafaoglu N, Herland A, Hasselkus R, Mannix R, FitzGerald EA, Prantil-Baun R, Watters A, Henry O, Benz M, Sanchez H, McCrea HJ, Goumnerova LC, Song HW, Palecek SP, Shusta E, Ingber DE (2019) Hypoxia-enhanced blood-brain barrier chip recapitulates human barrier function and shuttling of drugs and antibodies. Nature Communications 10:2621. https:// doi.org/10.1038/s41467-019-10588-0

140. Pesl M, Pribyl J, Acimovic I, Vilotic A, Jelinkova S, Salykin A, Lacampagne A, Dvorak P, Meli AC, Skladal P, Rotrekl V (2016) Atomic force microscopy combined with human pluripotent stem cell derived cardiomyocytes for biomechanical sensing. Biosens Bioelectron 85:751-757. https://doi.org/10.1016/j.bios.2016.05.073

141. Pinto AR, Ilinykh A, Ivey MJ, Kuwabara JT, D'Antoni ML, Debuque R, Chandran A, Wang L, Arora K, Rosenthal NA, Tallquist MD (2016) Revisiting cardiac cellular composition. Circ Res 118:400-409. https://doi.org/10.1161/CIRCRESAHA. 115.307778

142. Poon EN-Y, Luo X, Webb SE, Yan B, Zhao R, Wu SCM, Yang Y, Zhang P, Bai H, Shao J, Chan CM, Chan GC-F, Tsang SY,
Gundry RL, Yang H-T, Boheler KR (2020) The cell surface marker CD36 selectively identifies matured, mitochondria-rich hPSCcardiomyocytes. Cell Research 30:626-629. https://doi.org/10. 1038/s41422-020-0292-y

143. Pratt CM, Hertz RP, Ellis BE, Crowell SP, Louv W, Moyé L (1994) Risk of developing life-threatening ventricular arrhythmia associated with tefenadine in comparison with over-the-counter antihistamines, ibuprofen and clemastine. Am J Cardiol 73:346352. https://doi.org/10.1016/0002-9149(94)90006-x

144. Prot JM, Briffaut A-S, Letourneur F, Chafey P, Merlier F, Grandvalet Y, Legallais C, Leclerc E (2011) Integrated proteomic and transcriptomic investigation of the acetaminophen toxicity in liver microfluidic biochip. PLoS One 6:e21268. https://doi.org/ 10.1371/journal.pone.0021268

145. Protze SI, Liu J, Nussinovitch U, Ohana L, Backx PH, Gepstein L, Keller GM (2017) Sinoatrial node cardiomyocytes derived from human pluripotent cells function as a biological pacemaker. Nat Biotechnol 35:56-68. https://doi.org/10.1038/nbt.3745

146. Puluca N, Lee S, Doppler S, Münsterer A, Dreßen M, Krane M, Wu SM (2019) Bioprinting Approaches to Engineering Vascularized 3D Cardiac Tissues. Curr Cardiol Rep 21:90. https://doi.org/10.1007/s11886-019-1179-8

147. Qian F, Huang C, Lin Y-D, Ivanovskaya AN, O'Hara TJ, Booth RH, Creek CJ, Enright HA, Soscia DA, Belle AM, Liao R, Lightstone FC, Kulp KS, Wheeler EK (2017) Simultaneous electrical recording of cardiac electrophysiology and contraction on chip. Lab Chip 17:1732-1739. https://doi.org/10.1039/ C7LC00210F

148. Qin J, Wang Y, Wang L, Zhu Y (2018) Human brain organoid-ona-chip to model prenatal nicotine exposure. Lab on a Chip 18. https://doi.org/10.1039/C7LC01084B

149. Rajan SAP, Aleman J, Wan M, Pourhabibi Zarandi N, Nzou G, Murphy S, Bishop CE, Sadri-Ardekani H, Shupe T, Atala A, Hall AR, Skardal A (2020) Probing prodrug metabolism and reciprocal toxicity with an integrated and humanized multi-tissue organ-ona-chip platform. Acta Biomater 106:124-135. https://doi.org/10. 1016/j.actbio.2020.02.015

150. Redfern WS, Carlsson L, Davis AS, Lynch WG, MacKenzie I, Palethorpe S, Siegl PKS, Strang I, Sullivan AT, Wallis R, Camm AJ, Hammond TG (2003) Relationships between preclinical cardiac electrophysiology, clinical QT interval prolongation and torsade de pointes for a broad range of drugs: evidence for a provisional safety margin in drug development. Cardiovasc Res 58:3245. https://doi.org/10.1016/s0008-6363(02)00846-5

151. Research $\mathrm{C}$ for DE and (2020) S7B nonclinical evaluation of the potential for delayed ventricular repolarization (QT interval prolongation) by human pharmaceuticals. In: U.S. Food and Drug Administration. https://www.fda.gov/regulatory-information/ search-fda-guidance-documents/s7b-nonclinical-evaluationpotential-delayed-ventricular-repolarization-qt-intervalprolongation. Accessed 27 Jan 2021

152. Ribeiro MC, Slaats RH, Schwach V, Rivera-Arbelaez JM, Tertoolen LGJ, van Meer BJ, Molenaar R, Mummery CL, Claessens MMAE, Passier R (2020) A cardiomyocyte show of force: A fluorescent alpha-actinin reporter line sheds light on human cardiomyocyte contractility versus substrate stiffness. J Mol Cell Cardiol 141:54-64. https://doi.org/10.1016/j.yjmec.2020.03.008

153. Rocchetti M, Sala L, Dreizehnter L, Crotti L, Sinnecker D, Mura M, Pane LS, Altomare C, Torre E, Mostacciuolo G, Severi S, Porta A, De Ferrari GM, George AL, Schwartz PJ, Gnecchi M, Moretti A, Zaza A (2017) Elucidating arrhythmogenic mechanisms of long-QT syndrome CALM1-F142L mutation in patient-specific induced pluripotent stem cell-derived cardiomyocytes. Cardiovasc Res 113:531-541. https://doi.org/ $10.1093 / \mathrm{cvr} / \mathrm{cvx} 006$ 
154. da Rocha AM, Campbell K, Mironov S, Jiang J, Mundada L, Guerrero-Serna G, Jalife J, Herron TJ (2017) hiPSC-CM monolayer maturation state determines drug responsiveness in high throughput pro-arrhythmia screen. Scientific Reports 7:13834. https://doi.org/10.1038/s41598-017-13590-y

155. Rodriguez ML, Graham BT, Pabon LM, Han SJ, Murry CE, Sniadecki NJ (2014) Measuring the contractile forces of human induced pluripotent stem cell-derived cardiomyocytes with arrays of microposts. J Biomech Eng 136:051005. https://doi.org/10. $1115 / 1.4027145$

156. Ronaldson-Bouchard K, Ma SP, Yeager K, Chen T, Song L, Sirabella D, Morikawa K, Teles D, Yazawa M, VunjakNovakovic G (2018) Advanced maturation of human cardiac tissue grown from pluripotent stem cells. Nature 556:239-243. https://doi.org/10.1038/s41586-018-0016-3

157. Ruan J-L, Tulloch NL, Razumova MV, Saiget M, Muskheli V, Pabon L, Reinecke H, Regnier M, Murry CE (2016) Mechanical stress conditioning and electrical stimulation promote contractility and force maturation of induced pluripotent stem cell-derived human cardiac tissue. Circulation 134:1557-1567. https://doi.org/10. 1161/CIRCULATIONAHA.114.014998

158. Sager PT, Gintant G, Turner JR, Pettit S, Stockbridge N (2014) Rechanneling the cardiac proarrhythmia safety paradigm: a meeting report from the Cardiac Safety Research Consortium. Am Heart J 167:292-300. https://doi.org/10.1016/j.ahj.2013.11.004

159. Sakai K, Shimba K, Ishizuka K, Yang Z, Oiwa K, Takeuchi A, Kotani K, Jimbo Y (2017) Functional innervation of human induced pluripotent stem cell-derived cardiomyocytes by co-culture with sympathetic neurons developed using a microtunnel technique. Biochem Biophys Res Commun 494:138-143. https://doi. org/10.1016/j.bbrc.2017.10.065

160. Sakamiya M, Fang Y, Mo X, Shen J, Zhang T (2020) A heart-ona-chip platform for online monitoring of contractile behavior via digital image processing and piezoelectric sensing technique. Medical Engineering \& Physics 75:36-44. https://doi.org/10. 1016/j.medengphy.2019.10.001

161. Sala L, van Meer BJ, Tertoolen LGJ, Bakkers J, Bellin M, Davis RP, Denning C, Dieben MAE, Eschenhagen T, Giacomelli E, Grandela C, Hansen A, Holman ER, Jongbloed MRM, Kamel SM, Koopman CD, Lachaud Q, Mannhardt I, Mol MPH, Mosqueira D, Orlova VV, Passier R, Ribeiro MC, Saleem U, Smith GL, Burton FL, Mummery CL (2018) MUSCLEMOTION: a versatile open software tool to quantify cardiomyocyte and cardiac muscle contraction in vitro and in vivo. Circ Res 122:e5-e16. https://doi.org/10.1161/ CIRCRESAHA.117.312067

162. Sayed N, Ameen M, Wu JC (2019) Personalized medicine in cardio-oncology: the role of induced pluripotent stem cell. Cardiovasc Res 115:949-959. https://doi.org/10.1093/cvr/cvz024

163. Schaefer JA, Guzman PA, Riemenschneider SB, Kamp TJ, Tranquillo RT (2018) A cardiac patch from aligned microvessel and cardiomyocyte patches. J Tissue Eng Regen Med 12:546556. https://doi.org/10.1002/term.2568

164. Schneider O, Zeifang L, Fuchs S, Sailer C, Loskill P (2019) Userfriendly and parallelized generation of human induced pluripotent stem cell-derived microtissues in a centrifugal heart-on-a-chip. Tissue Eng Part A 25:786-798. https://doi.org/10.1089/ten.TEA. 2019.0002

165. Schweizer PA, Darche FF, Ullrich ND, Geschwill P, Greber B, Rivinius R, Seyler C, Müller-Decker K, Draguhn A, Utikal J, Koenen M, Katus HA, Thomas D (2017) Subtype-specific differentiation of cardiac pacemaker cell clusters from human induced pluripotent stem cells. Stem Cell Res Ther 8:229. https://oi.org/ 10.1186/s13287-017-0681-4

166. Seidman A, Hudis C, Pierri MK, Shak S, Paton V, Ashby M, Murphy M, Stewart SJ, Keefe D (2002) Cardiac dysfunction in the trastuzumab clinical trials experience. J Clin Oncol 20:12151221. https://doi.org/10.1200/JCO.2002.20.5.1215

167. Shafaattalab S, Lin E, Christidi E, Huang H, Nartiss Y, Garcia A, Lee J, Protze S, Keller G, Brunham L, Tibbits GF, Laksman Z (2019) Ibrutinib displays atrial-specific toxicity in human stem cell-derived cardiomyocytes. Stem Cell Reports 12:996-1006. https://doi.org/10.1016/j.stemcr.2019.03.011

168. Sharma A, Burridge PW, McKeithan WL, Serrano R, Shukla P, Sayed N, Churko JM, Kitani T, Wu H, Holmström A, Matsa E, Zhang Y, Kumar A, Fan AC, Del Álamo JC, Wu SM, Moslehi JJ, Mercola M, Wu JC (2017) High-throughput screening of tyrosine kinase inhibitor cardiotoxicity with human induced pluripotent stem cells. Sci Transl Med 9. https://doi.org/10.1126/ scitranslmed.aaf 2584

169. Shinozawa T, Nakamura K, Shoji M, Morita M, Kimura M, Furukawa H, Ueda H, Shiramoto M, Matsuguma K, Kaji Y, Ikushima I, Yono M, Liou S-Y, Nagai H, Nakanishi A, Yamamoto K, Izumo S (2017) Recapitulation of clinical individual susceptibility to drug-induced QT prolongation in healthy subjects using iPSC-derived cardiomyocytes. Stem Cell Reports 8: 226-234. https://doi.org/10.1016/j.stemcr.2016.12.014

170. Sicouri S, Antzelevitch C (2018) Mechanisms underlying the actions of antidepressant and antipsychotic drugs that cause sudden cardiac arrest. Arrhythm Electrophysiol Rev 7:199-209. https:// doi.org/10.15420/aer.2018.29.2

171. Sidorov VY, Samson PC, Sidorova TN, Davidson JM, Lim CC, Wikswo JP (2017) I-Wire Heart-on-a-Chip I: three-dimensional cardiac tissue constructs for physiology and pharmacology. Acta Biomater 48:68-78. https://doi.org/10.1016/j.actbio.2016.11.009

172. Sleiman Y, Souidi M, Kumar R, Yang E, Jaffré F, Zhou T, Bernardin A, Reiken S, Cazorla O, Kajava AV, Moreau A, Pasquié J-L, Marks AR, Lerman BB, Chen S, Cheung JW, Evans T, Lacampagne A, Meli AC (2020) Modeling polymorphic ventricular tachycardia at rest using patient-specific induced pluripotent stem cell-derived cardiomyocytes. EBioMedicine:60. https://doi.org/10.1016/j.ebiom.2020.103024

173. Spearman BS, Hodge AJ, Porter JL, Hardy JG, Davis ZD, Xu T, Zhang X, Schmidt CE, Hamilton MC, Lipke EA (2015) Conductive interpenetrating networks of polypyrrole and polycaprolactone encourage electrophysiological development of cardiac cells. Acta Biomaterialia 28:109-120. https://doi.org/10. 1016/j.actbio.2015.09.025

174. Stack JP, Moslehi J, Sayed N, Wu JC (2019) Cancer therapyinduced cardiomyopathy: can human induced pluripotent stem cell modelling help prevent it? Eur Heart J 40:1764-1770. https://doi.org/10.1093/eurheartj/ehx811

175. Sticker D, Rothbauer M, Ehgartner J, Steininger C, Liske O, Liska R, Neuhaus W, Mayr T, Haraldsson T, Kutter JP, Ertl P (2019) Oxygen management at the microscale: a functional biochip material with long-lasting and tunable oxygen scavenging properties for cell culture applications. ACS Appl Mater Interfaces 11:9730 9739. https://doi.org/10.1021/acsami.8b19641

176. Sun N, Yazawa M, Liu J, Han L, Sanchez-Freire V, Abilez OJ, Navarrete EG, Hu S, Wang L, Lee A, Pavlovic A, Lin S, Chen R, Hajjar RJ, Snyder MP, Dolmetsch RE, Butte MJ, Ashley EA, Longaker MT, Robbins RC, Wu JC (2012) Patient-specific induced pluripotent stem cells as a model for familial dilated cardiomyopathy. Sci Transl Med 4:130-147. https://doi.org/10.1126/ scitranslmed.3003552

177. Takahashi K, Tanabe K, Ohnuki M, Narita M, Ichisaka T, Tomoda K, Yamanaka S (2007) Induction of pluripotent stem cells from adult human fibroblasts by defined factors. Cell 131: 861-872. https://doi.org/10.1016/j.cell.2007.11.019

178. Tanaka T, Tohyama S, Murata M, Nomura F, Kaneko T, Chen H, Hattori F, Egashira T, Seki T, Ohno Y, Koshimizu U, Yuasa S, Ogawa S, Yamanaka S, Yasuda K, Fukuda K (2009) In vitro 
pharmacologic testing using human induced pluripotent stem cellderived cardiomyocytes. Biochem Biophys Res Commun 385: 497-502. https://doi.org/10.1016/j.bbrc.2009.05.073

179. Tandon N, Cannizzaro C, Chao P-HG, Maidhof R, Marsano A, Au HTH, Radisic M, Vunjak-Novakovic G (2009) Electrical stimulation systems for cardiac tissue engineering. Nature Protocols 4: 155-173. https://doi.org/10.1038/nprot.2008.183

180. Tocchetti CG, Cadeddu C, Di Lisi D, Femminò S, Madonna R, Mele D, Monte I, Novo G, Penna C, Pepe A, Spallarossa P, Varricchi G, Zito C, Pagliaro P, Mercuro G (2019) From molecular mechanisms to clinical management of antineoplastic druginduced cardiovascular toxicity: a translational overview. Antioxid Redox Signal 30:2110-2153. https://doi.org/10.1089/ ars.2016.6930

181. Toepfer CN, Sharma A, Cicconet M, Garfinkel AC, Mücke M, Neyazi M, Willcox JAL, Agarwal R, Schmid M, Rao J, Ewoldt J, Pourquié O, Chopra A, Chen CS, Seidman JG, Seidman CE (2019) SarcTrack. Circ Res 124:1172-1183. https://doi.org/10. 1161/CIRCRESAHA.118.314505

182. Tohyama S, Hattori F, Sano M, Hishiki T, Nagahata Y, Matsuura T, Hashimoto H, Suzuki T, Yamashita H, Satoh Y, Egashira T, Seki T, Muraoka N, Yamakawa H, Ohgino Y, Tanaka T, Yoichi M, Yuasa S, Murata M, Suematsu M, Fukuda K (2013) Distinct metabolic flow enables large-scale purification of mouse and human pluripotent stem cell-derived cardiomyocytes. Cell Stem Cell 12:127-137. https://doi.org/10.1016/j.stem.2012.09.013

183. Tsui JH, Ostrovsky-Snider NA, Yama DMP, Donohue JD, Choi JS, Chavanachat R, Larson JD, Murphy AR, Kim D-H (2018) Conductive silk-polypyrrole composite scaffolds with bioinspired nanotopographic cues for cardiac tissue engineering. J Mater Chem B 6:7185-7196. https://doi.org/10.1039/C8TB01116H

184. Tsukamoto Y, Akagi T, Akashi M (2020) Vascularized cardiac tissue construction with orientation by layer-by-layer method and 3D printer. Scientific Reports 10:5484. https://doi.org/10.1038/ s41598-020-59371-y

185. Tulloch NL, Veronica M, Razumova MV, Steven KF, Michael R, Hauch KD, Lil P, Hans R, Murry CE (2011) Growth of engineered human myocardium with mechanical loading and vascular coculture. Circulation Research 109:47-59. https://doi.org/10.1161/ CIRCRESAHA.110.237206

186. Vollert I, Seiffert M, Bachmair J, Sander M, Eder A, Conradi L, Vogelsang A, Schulze T, Uebeler J, Holnthoner W, Redl H, Reichenspurner H, Hansen A, Eschenhagen T (2014) In vitro perfusion of engineered heart tissue through endothelialized channels. Tissue Eng Part A 20:854-863. https://doi.org/10.1089/ten.TEA. 2013.0214

187. Wang G, McCain ML, Yang L, He A, Pasqualini FS, Agarwal A, Yuan H, Jiang D, Zhang D, Zangi L, Geva J, Roberts AE, Ma Q, Ding J, Chen J, Wang D, Li K, Wang J, Wanders RJA, Kulik W, Vaz FM, Laflamme MA, Murry CE, Chien KR, Kelley RI, Church GM, Parker KK, Pu WT (2014) Modeling the mitochondrial cardiomyopathy of Barth syndrome with iPSC and heart-on-chip technologies. Nat Med 20:616-623. https://doi.org/10.1038/nm.3545

188. Wanjare M, Hou L, Nakayama KH, Kim JJ, Mezak NP, Abilez OJ, Tzatzalos E, Wu JC, Huang NF (2017) Anisotropic microfibrous scaffolds enhance the organization and function of cardiomyocytes derived from induced pluripotent stem cells. Biomater Sci 5:1567-1578. https://doi.org/10.1039/c7bm00323d

189. Wilmer MJ, Ng CP, Lanz HL, Vulto P, Suter-Dick L, Masereeuw R (2016) Kidney-on-a-chip technology for drug-induced nephrotoxicity screening. Trends Biotechnol 34:156-170. https://doi.org/ 10.1016/j.tibtech.2015.11.001

190. van der Worp HB, Howells DW, Sena ES, Porritt MJ, Rewell S, O'Collins V, Macleod MR (2010) Can animal models of disease reliably inform human studies? PLOS Medicine 7:e1000245. https://doi.org/10.1371/journal.pmed.1000245
191. Wyles SP, Li X, Hrstka SC, Reyes S, Oommen S, Beraldi R, Edwards J, Terzic A, Olson TM, Nelson TJ (2016) Modeling structural and functional deficiencies of RBM20 familial dilated cardiomyopathy using human induced pluripotent stem cells. Hum Mol Genet 25: 254-265. https://doi.org/10.1093/hmg/ddv468

192. Y Z, N R, Ey W, Nt F, Bfl L, Ej K-W, Ph B, M R (2020) Engineering microenvironment for human cardiac tissue assembly in heart-on-a-chip platform. In: Matrix biology : journal of the International Society for Matrix Biology. https://pubmed.ncbi. nlm.nih.gov/30981898/. Accessed 26 Jan 2021

193. Yang X, Pabon L, Murry CE (2014) Engineering adolescence: maturation of human pluripotent stem cell-derived cardiomyocytes. Circ Res 114:511-523. https://doi.org/10.1161/ CIRCRESAHA.114.300558

194. Yin L, Du G, Zhang B, Zhang H, Yin R, Zhang W, Yang S-M (2020) Efficient drug screening and nephrotoxicity assessment on co-culture microfluidic kidney chip. Scientific Reports 10:6568. https://doi.org/10.1038/s41598-020-63096-3

195. Yin S, Zhang X, Zhan C, Wu J, Xu J, Cheung J (2005) Measuring single cardiac myocyte contractile force via moving a magnetic bead. Biophys J 88:1489-1495. https://doi.org/10.1529/biophysj. 104.048157

196. Yu J, Peng S, Luo D, March JC (2012) In vitro 3D human small intestinal villous model for drug permeability determination. Biotechnol Bioeng 109:2173-2178. https://doi.org/10.1002/bit.24518

197. Zhang D, Shadrin IY, Lam J, Xian H-Q, Snodgrass HR, Bursac N (2013) Tissue-engineered cardiac patch for advanced functional maturation of human ESC-derived cardiomyocytes. Biomaterials 34: 5813-5820. https://doi.org/10.1016/j.biomaterials.2013.04.026

198. Zhang W, Kong CW, Tong MH, Chooi WH, Huang N, Li RA, Chan BP (2017) Maturation of human embryonic stem cell-derived cardiomyocytes (hESC-CMs) in 3D collagen matrix: Effects of niche cell supplementation and mechanical stimulation. Acta Biomater 49: 204-217. https://doi.org/10.1016/j.actbio.2016.11.058

199. Zhang Y, Long C, Li H, McAnally JR, Baskin KK, Shelton JM, Bassel-Duby R, Olson EN (2017) CRISPR-Cpf1 correction of muscular dystrophy mutations in human cardiomyocytes and mice. Science Advances 3:e1602814. https://doi.org/10.1126/ sciadv. 1602814

200. Zhang YS, Arneri A, Bersini S, Shin S-R, Zhu K, GoliMalekabadi Z, Aleman J, Colosi C, Busignani F, Dell'Erba V, Bishop C, Shupe T, Demarchi D, Moretti M, Rasponi M, Dokmeci MR, Atala A, Khademhosseini A (2016) Bioprinting 3D microfibrous scaffolds for engineering endothelialized myocardium and heart-on-a-chip. Biomaterials 110:45-59. https://doi. org/10.1016/j.biomaterials.2016.09.003

201. Zhao M, Shoji E, Sakurai H (2018) In vitro evaluation of exon skipping in disease-specific iPSC-derived myocytes. Methods Mol Biol 1828:173-189. https://doi.org/10.1007/978-1-4939-8651-4_11

202. Zhao Y, Rafatian N, Feric NT, Cox BJ, Aschar-Sobbi R, Wang EY, Aggarwal P, Zhang B, Conant G, Ronaldson-Bouchard K, Pahnke A, Protze S, Lee JH, Davenport Huyer L, Jekic D, Wickeler A, Naguib HE, Keller GM, Vunjak-Novakovic G, Broeckel U, Backx PH, Radisic M (2019) A platform for generation of chamber-specific cardiac tissues and disease modeling. Cell 176:913-927.e18. https://doi.org/10.1016/j.cell.2018.11.042

203. Zhao Y, Rafatian N, Wang EY, Wu Q, Lai BFL, Lu RX, Savoji H, Radisic M (2020) Towards chamber specific heart-on-a-chip for drug testing applications. Adv Drug Deliv Rev 165-166:60-76. https://doi.org/10.1016/j.addr.2019.12.002

204. (2001) Neuroscience, 2nd ed. Sinauer Associates

Publisher's note Springer Nature remains neutral with regard to jurisdictional claims in published maps and institutional affiliations. 